FEDERAL RESERVE BANK OF SAN FRANCISCO

WORKING PAPER SERIES

\title{
International Evidence on Extending Sovereign Debt Maturities
}

\author{
Jens H. E. Christensen \\ Jose A. Lopez \\ Paul L. Mussche \\ Federal Reserve Bank of San Francisco \\ July 2021 \\ Working Paper 2021-19 \\ https://www.frbsf.org/economic-research/publications/working-papers/2021/19/
}

\section{Suggested citation:}

Christensen, Jens H. E., Jose A. Lopez, Paul L. Mussche. 2021 "International Evidence on Extending Sovereign Debt Maturities," Federal Reserve Bank of San Francisco Working Paper 2021-19. https://doi.org/10.24148/wp2021-19

The views in this paper are solely the responsibility of the authors and should not be interpreted as reflecting the views of the Federal Reserve Bank of San Francisco or the Board of Governors of the Federal Reserve System. 


\title{
International Evidence on Extending Sovereign Debt Maturities
}

\author{
Jens H. E. Christensen \\ Jose A. Lopez \\ Paul L. Mussche \\ Federal Reserve Bank of San Francisco \\ 101 Market Street \\ San Francisco, CA 94105
}

\begin{abstract}
Portfolio diversification is as important to debt management as it is to asset management. In this paper, we focus on diversification of sovereign debt issuance by examining the extension of the maximum maturity of issued debt. In particular, we examine the potential costs to the U.S. Treasury of introducing 50-year bonds as a financing option. Based on evidence from foreign government bond markets with such long-term debt, our results suggest that a 50-year Treasury bond would likely trade at an average yield that is at most 20 basis points above that of a 30-year bond. Our results based on extrapolations from a dynamic yield curve model using just U.S. Treasury yields are similar.
\end{abstract}

JEL Classification: E43, E47, G12, G13

Keywords: term structure modeling, yield extrapolation, debt management

We thank Nikola Mirkov and Thomas Nitschka for sharing the Swiss yield data with us. Furthermore, we thank Simon Zhu for outstanding research assistance. The views in this paper are solely the responsibility of the authors and not necessarily those of the Federal Reserve Bank of San Francisco or the Federal Reserve System.

This version: July 22, 2021. 


\section{Introduction}

Portfolio diversification is as important to debt management as it is to asset management. With respect to sovereign debt issuance, several studies have examined issues of time-varying maturity structure of debt as well as default resolution through maturity extension. ${ }^{1}$ In light of the significant fiscal consequences arising from the pandemic and its effect on economic uncertainty, questions regarding the magnitudes of sovereign bond issuance and the optimization of its issuance terms are worthy of further review. For the United States, at the end of 2020, the Treasury's total amount of outstanding marketable debt reached 20,980 billion dollars, rising by about 25\% from 16,682 billion dollars at the end of 2019 in a single calendar year. With most projections suggesting continued or increasing deficits, practical questions arise regarding how to finance them in a manner sustainable for both the U.S. government and financial markets.

In this paper, we examine a potentially relevant aspect of this sovereign debt management challenge; namely, whether the U.S. government might benefit from extending the maximum maturity of its debt issuance from its well-established 30 year point. Provided there is demand for such debt, its introduction potentially could open up new segments of investors to U.S. government debt.

Unfortunately, with no such debt trading in the Treasury market at this point, there is no direct way to gauge investor demand for this type of debt. ${ }^{2}$ Instead, we pursue two different approaches to assess the costs of long-term debt. In both approaches, we narrow the issuing decision to a single choice that we consider to be particularly realistic and relevant for the question at hand: Should the U.S. government issue a 50-year bond as an alternative to raising the same amount by issuing one of its regular 30-year Treasury bonds? This choice allows us to limit our focus to the pricing of 50-year bonds relative to that of 30-year bonds.

In the first exercise, we examine evidence from an international panel of government bond prices. Specifically, we study a total of four well-established government bond markets in which 50-year bonds have already been issued. For each market, we estimate a flexible dynamic term structure model using all available bond prices as recommended by Andreasen et al. (2019). This allows us to produce very accurate daily estimates of synthetic 30- and 50-year par yields. The difference between the two represents a measure of the added costs of issuing a 50-year bond instead of a 30-year bond. The results from these four markets indicate that the cost difference tends to fluctuate in a narrow range from -0.1 percent to 0.2 percent with a mild procyclical pattern.

Overall, these results imply with some confidence that a 50-year U.S. Treasury bond is likely to trade at a yield that will rarely exceed that of a 30-year bond by more than 0.2

\footnotetext{
${ }^{1}$ See Arellano and Ramanarayanan (2012) and Michalache (2020), respectively.

${ }^{2}$ See Garbade (2017a,b) for a discussion of historical periods for which the longest Treasury maturity was larger than 30 years.
} 
percent, or 20 basis points. This converts into one basis point increase in the bond yield for each added year of maturity in excess of 30 years. For comparison, we note that the yield spread between the ten-year and two-year U.S. Treasury note averaged 135.9 basis points, or 17.0 basis points per added year of maturity, over the past 30 years. ${ }^{3}$ This result suggests a relatively low tradeoff favoring issuance of 50-year bonds.

In the second exercise, we offer a quantification of this cost based on long-term yield extrapolations using Treasury yield data. To do so, we follow Christensen et al. (2021) and use the standard dynamic Nelson-Siegel (DNS) model described in Diebold and Li (2006) for such extrapolations. We estimate this model on a representative sample of weekly U.S. Treasury yields from the Gürkaynak et al. (2007) database covering the period from January 1995 to December 2020 with maturities up to 30 years. The estimated model allows us to calculate in-sample fitted 30-year par yields as well as out-of-sample extrapolated 50-year par yields. Again, the difference between these two model-implied series represents a measure of the added costs of issuing a 50-year bond relative to a 30-year bond. The results show that the difference almost entirely remains in the 0 to 0.2 percent range. The spread is near the top of this range when the yield curve is steep and very close to zero when the yield curve is flat or outright inverted, again pointing to a procyclical pattern in the cost difference.

Overall, the results from the two exercises are consistent with each other and provide evidence in favor of extending the maturity of debt issuance by the U.S. Treasury. While we analyze the issuance of 50-year Treasury bonds primarily from a pricing perspective, there are other potential benefits of such an issuance to various market participants. For example, the addition of a bond maturing well beyond the longest maturity bond outstanding would provide the market with both a pricing reference and a hedging instrument that far out the yield curve. The pricing reference can be used to price related securities or derivatives such as ultra-long maturity interest rate swaps (and possibly even cross-currency swaps into currencies with ultra-long issuance), corporate bonds, and possibly even long-dated infrastructure projects. This instrument may also be used to hedge long-dated corporate or swap positions (up to spread risk).

Secondly, periods of sustained government surpluses such as those in the 1990s ultimately led to the announcement of the suspension of 30-year issuance by the Treasury on October 31,2001 . This can lead to a loss of liquidity and pricing information in that sector as the bonds age out of it. The issuance of 50-year securities, even if ultimately suspended, would allow observable prices in the 30-year sector to remain available for a number of years after any suspension of 50-year issuance.

Thirdly, in the context of asset liability management (ALM), the availability of very long dated Treasuries would help at least in principle to reduce cash flow mismatches between

\footnotetext{
${ }^{3}$ These statistics are based on daily two- and ten-year zero-coupon yields from the Gürkaynak et al. (2007) database covering the 30-year period from January 2, 1991, to December 31, 2020.
} 
assets and liabilities for life insurance companies and pension funds in particular. ${ }^{4}$ These could be life insurance companies trying to hedge the reinvestment risk associated with the defeasance of liability cash flows stemming from very long-dated products such as term life or fixed annuities. They could also be used by defined benefit pension funds with lifetime payouts. We recognize that these participants will typically not find sufficient yield in very long-dated Treasury securities alone to manage the ALM risk, but it is possible to decouple the cash flow mismatch management to some degree from the yield seeking required to make the ALM activity economically viable. By this, we mean concentrating yield pick-up in the corporate bond sector out to, say, the 10 year maturity point where most of the corporate issuance resides anyway and leaving 30- and 50-year Treasury securities as ways of reducing cash flow mismatches between assets and liabilities.

The remainder of the paper is structured as follows. Section 2 contains the description of our international panel of government bond prices, while Section 3 provides a description of the no-arbitrage term structure model we use and summarizes our estimation results. Section 4 assesses the added cost of issuing 50-year bonds instead of 30-year bonds. Finally, Section 5 concludes the paper.

\section{The International Government Bond Data}

Several developed countries have issued sovereign debt with 50-year maturities. In this section, we describe the data from each of the four government bond markets-Austria, France, Switzerland, and the United Kingdom - that we use in our empirical analysis.

\subsection{Austrian Government Bond Data}

As of November 20, 2020, the total outstanding notional amount of marketable bonds issued by the Austrian central government was $€ 264$ billion, which is close to 65 percent of Austrian GDP. Despite the large relative size of its government bond market, the Austrian government holds a AA+ rating from all major rating agencies with a stable outlook. Thus, there is essentially no credit risk to account for in the bond price data from this market.

To estimate the factors in our yield curve model, we use the prices of standard Austrian fixed-coupon government bonds. These are all marketable, non-callable bonds denominated in euros that pay a fixed rate of interest annually. The total number of Austrian government bonds in our sample over time is shown in Figure 1(b). Early on the number of bonds is close to 60 , but it quickly decreases and reaches a low of 15 bonds by late 2007 with a slight gradual increase thereafter. The available universe of individual Austrian fixed-coupon government bonds since January 1999 is illustrated in Figure 1(a). It is the dispersion in the cross sectional distribution of the bonds that provide the identification of the factors within

\footnotetext{
${ }^{4}$ See Christensen et al. (2021) for further discussion.
} 


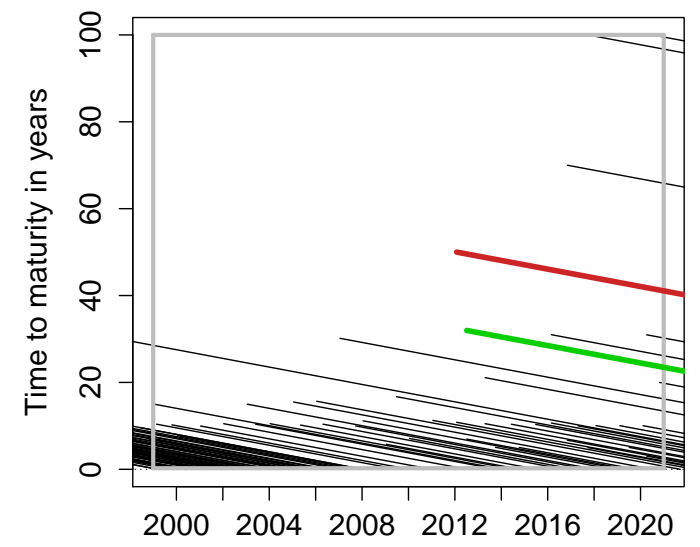

(a) Distribution of nominal bonds

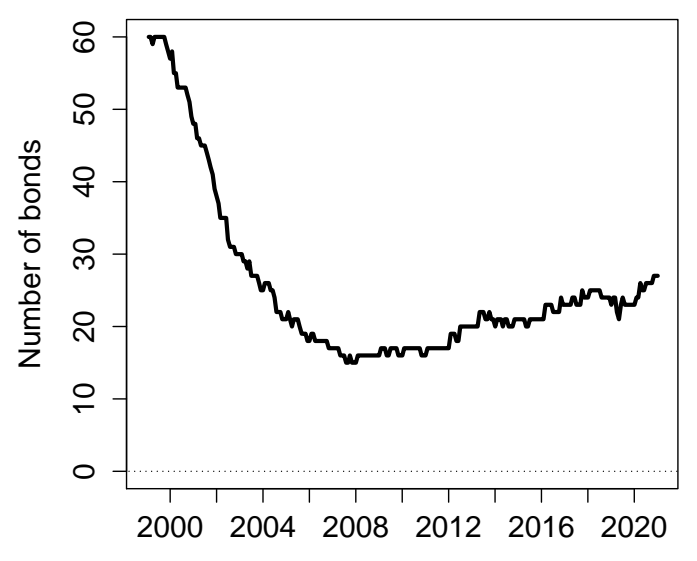

(b) Number of bonds

\section{Figure 1: Overview of the Austrian Government Bond Data}

Panel (a) shows the maturity distribution of all Austrian government bonds issued since 1999 including a few select bonds issued earlier. The solid grey rectangle indicates the sample used in our analysis, where the sample is restricted to start on January 31, 1999, and limited to nominal government bond prices with more than three months to maturity after issuance. Panel (b) reports the number of outstanding Austrian government bonds at a given point in time for various sample dates.

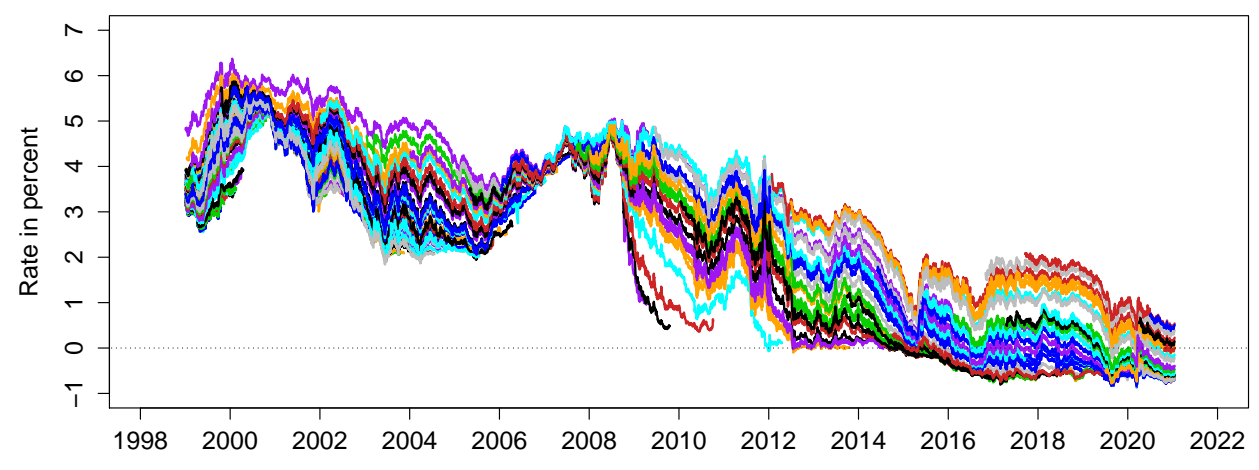

Figure 2: Yield to Maturity of Austrian Government Bonds

our model. Furthermore, we note that the Austrian government systematically has been issuing five- and ten-year bonds during this period. In addition, several long-term bonds with up to 100 years to maturity have been issued. For our analysis, we pay special attention to the 50-year bond issued in 2012, highlighted with a solid red line, and pair it with a 30-year bond issued around the same time and indicated with a solid green line. The difference in the pricing of these two bonds provides us with an empirical proxy for the added cost of issuing a 50-year bond over a 30-year bond. 
Figure 2 shows the yields to maturity series for all Austrian government bonds in our sample at daily frequency from January 1999 through the end of December 2020. The significant persistent decline in yields over this 22-year period is clearly visible. Austrian long-term nominal government bond yields were around 5 percent in the late 1990s and have dropped to close to zero by December 2020 .

Regarding the important question of a lower bound, the European Central Bank has already lowered its conventional policy rate well below zero. As a consequence, short- and medium-term Austrian bond yields have been significantly below zero since 2015 with no visible lower constraint. Thus, it is not clear that one would need to impose a lower bound to model these data. Empirically, it is in general challenging to determine whether an unconstrained Gaussian model approach is more appropriate than a model approach enforcing a lower bound in such cases, see Andreasen and Meldrum (2019) for a detailed discussion.

\subsection{French Government Bond Data}

This section briefly describes the French government bond data we use in the analysis. These are all standard French fixed-coupon government bonds, known as OATs. To give a sense of the size of the French government bond market, we note that, as of the end of November 2020, the total outstanding notional amount of marketable bonds issued by the French government was $€ 1,999$ billion. In terms of medium- and long-term debt, the outstanding notional amount was $€ 1,834$ billion of which $€ 220$ billion, or 12.0 percent, represented inflation-indexed securities. ${ }^{5}$ Despite the large size of the French government bond market, the French government still holds a AA rating from all major rating agencies with either a stable or a positive outlook. Thus, there is essentially no credit risk to account for in the French bond price data.

To estimate the factors in our model, we use the prices of standard French government fixed-coupon bonds. These are all marketable, non-callable bonds denominated in euros that pay a fixed rate of interest annually. The total number of such French government bonds in our sample over time is shown in Figure 3(b). Early on the number of bonds is about 10, but it quickly increases to about 40 bonds by 2010 with a slight additional increase thereafter. The available universe of individual French government fixed-coupon bonds since January 1999 is illustrated in Figure 3(a). ${ }^{6}$ It is the dispersion in the cross sectional distribution of the bonds that provide the identification of the factors within our model. We note that the French government systematically has been issuing two-, five-, ten-, 15-, and 30-year fixed-coupon bonds during this period. In addition, a total of three 50-year bonds have been issued since 2005. These are highlighted with solid red lines in the figure. Also highlighted with solid green lines are matching 30-year bonds issued around the same time as the 50-year bonds. In our analysis, we will examine the yield differences of these bond pairs, which roughly have

\footnotetext{
${ }^{5}$ This information is available at https://www.aft.gouv.fr/files/medias-aft/7_Publications/7.2_BM/367_Monthly\%20bulletin\%20december\%202020.pdf

${ }^{6}$ Our sample represents an update of the French bond data analyzed by Christensen at al. (2021).
} 


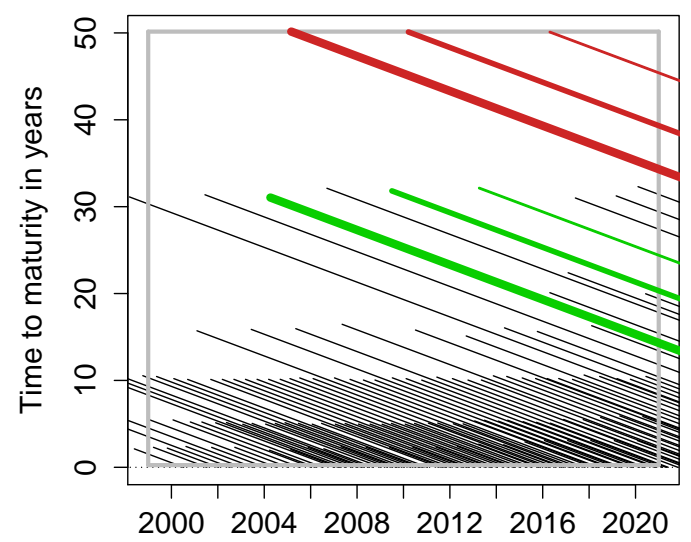

(a) Distribution of nominal bonds

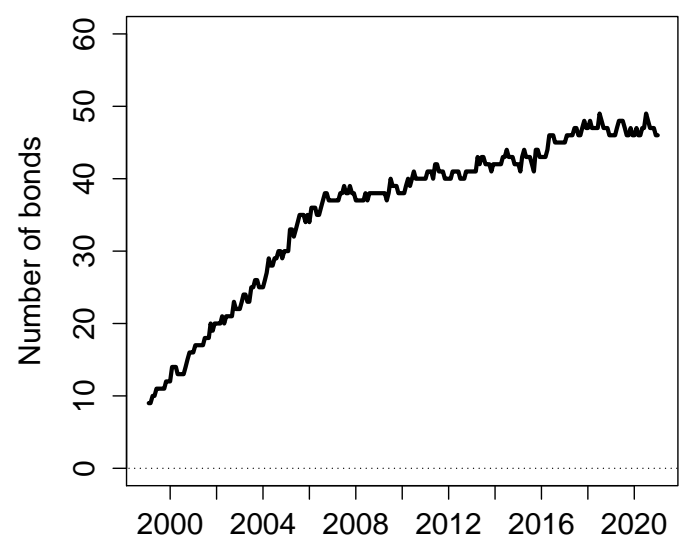

(b) Number of nominal bonds

Figure 3: Overview of the French Government Bond Data

Panel (a) shows the maturity distribution of all French fixed-coupon government bonds issued since 1999 including a few select bonds issued earlier. The solid grey rectangle indicates the sample used in our analysis, where the sample is restricted to start on January 4, 1999, and limited to nominal government bond prices with more than three months to maturity after issuance. Panel (b) reports the number of outstanding French nominal government bonds at each date in the sample.

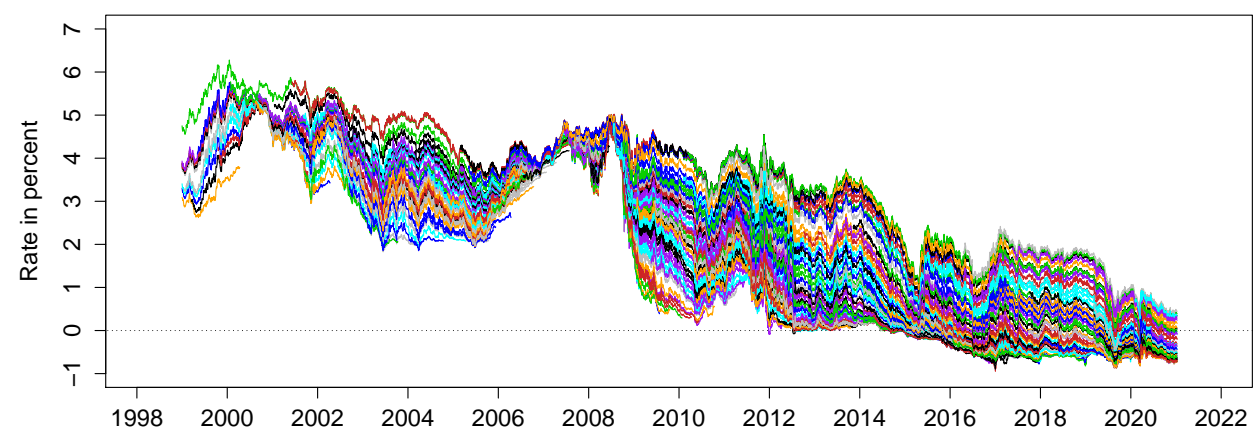

Figure 4: Yield to Maturity of French Government Bonds

a maturity difference of 20 years and hence offers an empirical proxy for the excess costs of issuing 50-year bonds over 30-year bonds.

Figure 4 shows the yields to maturity for all French government bonds in our sample at daily frequency from January 1999 through the end of December 2020. The significant persistent decline in French yields over this 22-year period is clearly visible. French long-term government bond yields were close to 5 percent in the early 2000s and have dropped to a level below 1 percent by December 2020. 


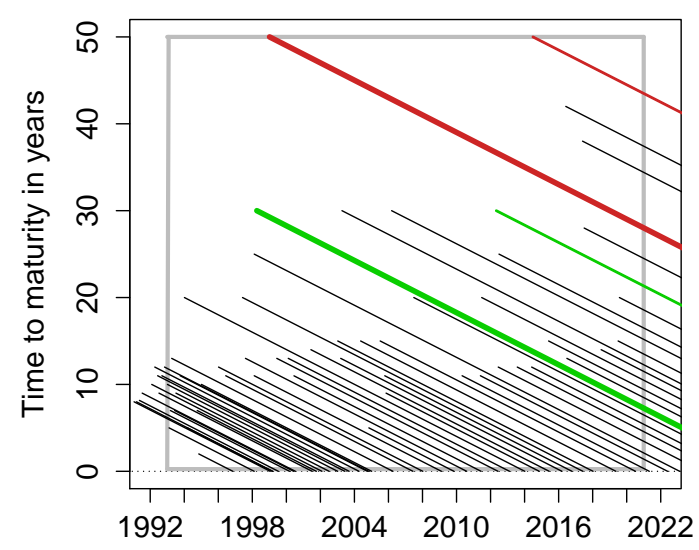

(a) Maturity distribution of bonds

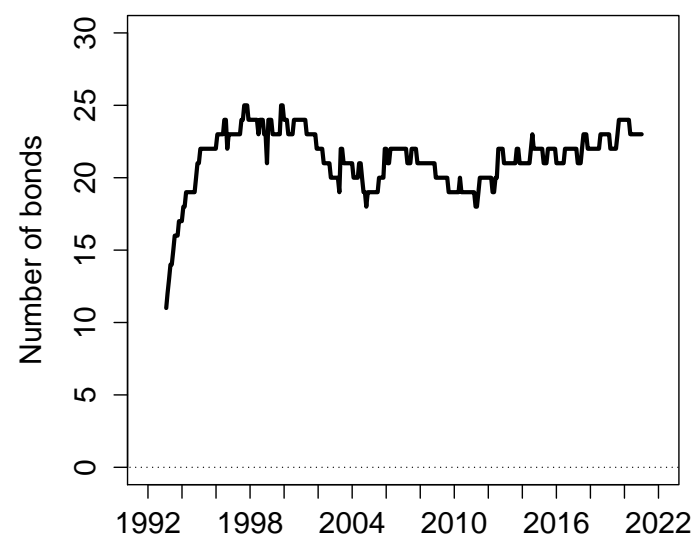

(b) Number of bonds

Figure 5: The Swiss Government Bond Market

Panel (a) shows the maturity distribution of the Swiss Confederation bonds considered. The solid grey rectangle indicates the subsample used. Panel (b) reports the number of Swiss Confederation bonds at each date.

As with the Austrian data, short- and medium-term French bond yields have been significantly below zero since 2015 thanks to the introduction of negative policy rates by the ECB. Thus, it is not clear that one would need to impose a lower bound to model these data, which supports our choice to focus on Gaussian models.

\subsection{Swiss Government Bond Data}

In comparison to the previous two markets, the Swiss government bond market is small, even relative to the Swiss economy. As of January 7, 2021, the total amount of outstanding Swiss government bonds was CHF67 billion, or less than 10 percent of Swiss nominal GDP in 2020. For that same reason, Switzerland holds a AAA rating with all major rating agencies. Thus, these bonds are among the safest in the world.

Our Swiss government bond price data are collected daily by staff at the Swiss National Bank and are available back to the 1980s. However, an inspection of the data reveals that the early part of the sample is characterized by many stale or erratic prices. For these reasons we choose to start the data sample in January 1993, a date at which the data appear to be systematically reliable across all available bonds. For the purposes of factor identification, our model needs at least five bonds to be traded on each day in the sample. As a consequence, we track a few select bonds that were issued before January 1993 and appear to have reliable prices. Importantly, the sample contains every Swiss government bond issued since 1993. Thus, our analysis is complete and comprehensive for the period since then and performed at 


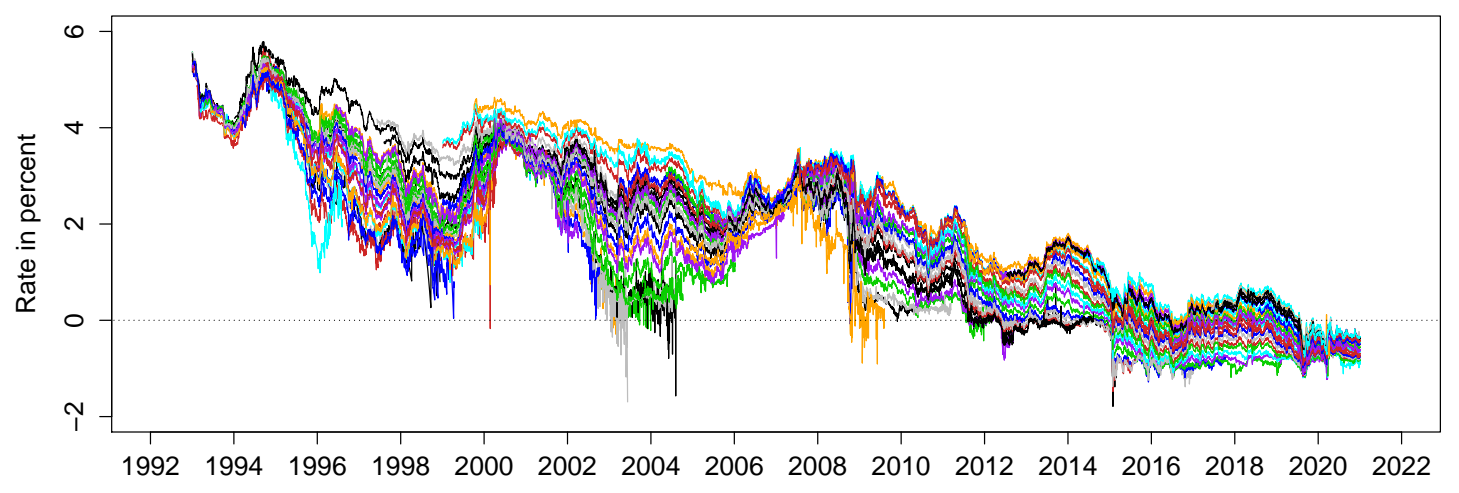

Figure 6: Yield to Maturity of Swiss Government Bonds

daily frequency. ${ }^{7}$

Figure 5(a) shows the maturity distribution of the universe of Swiss government bonds across time since 1993. The vertical solid grey lines indicate the start and end dates for our sample, while the horizontal solid grey lines indicate the top and bottom of the maturity range considered. The top of the range equals 50 years and is determined by the longest bond maturity issued by the Swiss Confederation, while the bottom of the range is fixed at three months to avoid erratic price patterns for bonds as they approach maturity, see Gürkaynak et al. (2007). Like in the previous two markets, we are able to match each of the two 50-year bonds issued by the Swiss government - shown with solid red lines - with a corresponding 30year bond issued around the same time, each highlighted with a solid green line. As before, the price differences of these two bond pairs provide an empirical proxy for the cost difference between 30- and 50-year bonds.

Figure 5(b) shows the number of bonds in our sample at each point in time. We note that the total number of outstanding bonds have been fairly stable since the mid-1990s. At the end of our sample period, a total of 22 bonds remained outstanding.

Figure 6 shows the Swiss government bond prices converted into yield to maturity. Note the following regarding these yield series. First, yield levels have generally trended lower during this 28-year period, ranging from close to 5 percent in the early 1990s to below zero by the end of our sample. Second, business cycle variation in the shape of the yield curve is pronounced around the lower trend. The yield curve tends to flatten ahead of recessions and steepen during the initial phase of economic recoveries. It is these characteristics that are the practical motivation behind our choice of using a five-factor model for the Swiss yield curve similar to what we do for the other countries in our sample.

\footnotetext{
${ }^{7}$ Our sample represents an update of the Swiss bond data used by both Christensen at al. (2021) and Christensen and Mirkov (2021).
} 


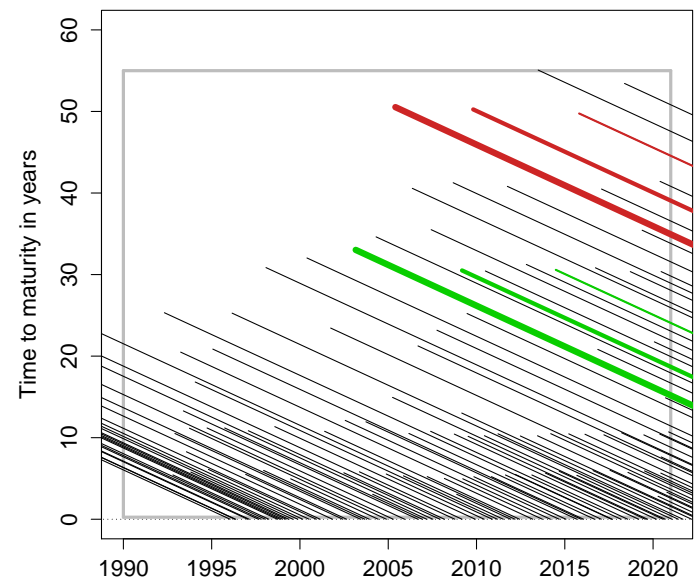

(a) Distribution of nominal bonds

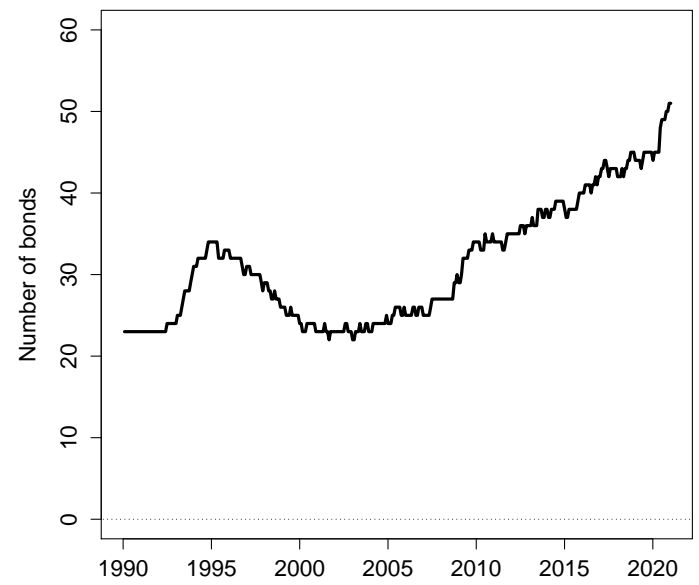

(b) Number of bonds

\section{Figure 7: Overview of the U.K. Government Bond Data}

Panel (a) shows the maturity distribution of all U.K. government bonds issued since 1990 including several bonds issued earlier. The solid grey rectangle indicates the sample used in our analysis, where the sample is restricted to start on January 4, 1990, and limited to nominal government bond prices with more than three months to maturity after issuance. Panel (b) reports the number of outstanding U.K. government bonds at a given point in time for various sample dates.

\subsection{U.K. Government Bond Data}

This final section briefly describes the U.K. government bond data we analyze. To give a sense of the size of its government bond market, we note that, as of the end of September 2020, the total outstanding notional amount of marketable bonds issued by the U.K. government was $£ 1,916$ billion of which $£ 450$ billion represented index-linked gilts, or 23.5 percent. Despite the large size of the U.K. government bond market, the U.K. government holds an AA-rating from the major rating agencies. Thus, there is at most modest credit risk to account for in the U.K. bond price data.

To estimate the factors in our model, we use the prices of standard U.K. fixed-coupon gilts. These are all marketable, non-callable bonds denominated in British pounds that pay a fixed rate of interest semi-annually. The total number of U.K. gilts in our sample over time is shown in Figure 7(b). Early on the number of bonds varied between 20 and 30. However, since 2005 the number of bonds has increased persistently thanks to the long maturities of the gilts issued since then. By the end of 2020 there are more than 50 gilts in our sample. The available universe of individual U.K. gilts since January 1990 is illustrated in Figure 7(a). We note that the U.K. debt management office has systematically issued a wide range of different gilts during our sample period. Of particular interest is the fact that a total of three 50-year gilts have been issued and can each be paired with a 30-year bond issued around the same time. These are highlighted in the figure with solid red and green lines, respectively. The 


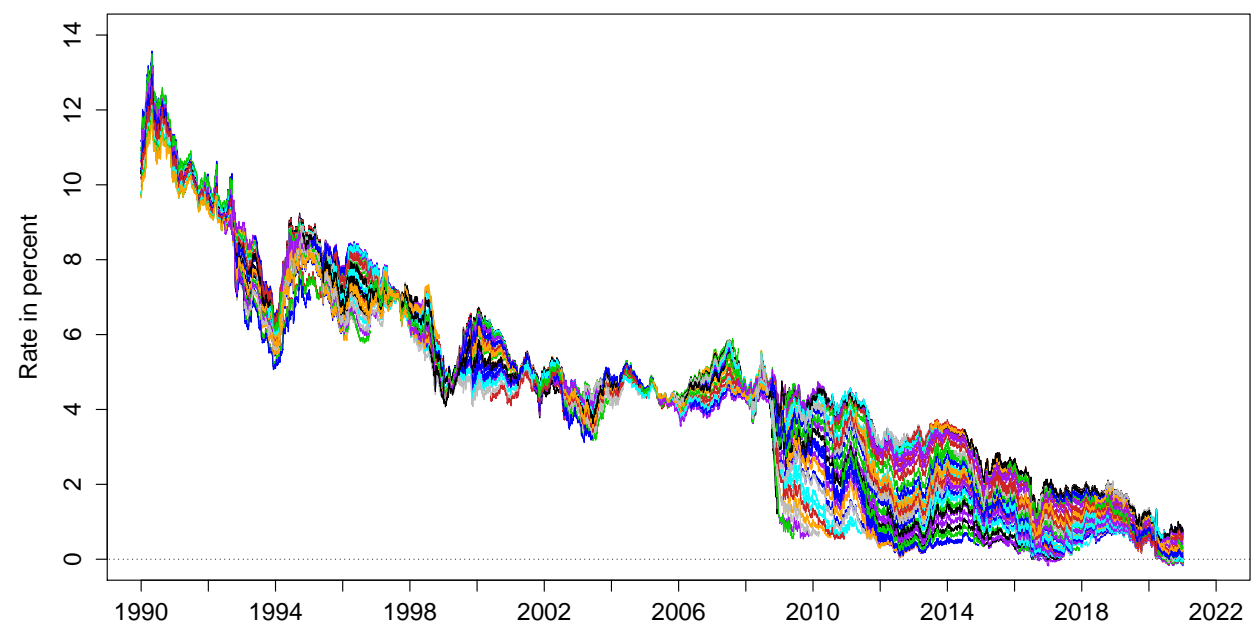

Figure 8: Yield to Maturity of U.K. Government Bonds

pricing of these bond pairs provides an empirical proxy for the excess costs of issuing 50-year bonds over 30-year bonds in this market.

Figure 8 shows the yields to maturity series for all U.K. gilts in our sample from January 1990 to December 2020. The persistent and sizable decline in U.K. yields during this 30-year period is clearly visible. U.K. long-term nominal government bond yields were close to 12 percent in the early 1990s and have dropped to around 1 percent by December 2020 .

Regarding the important question of a lower bound, we note that short- and mediumterm gilts with maturities up to six years have traded at negative yields for extended periods despite the fact that the Bank of England has stated that it does not plan to introduce negative interest rates and never intends to lower the Bank Rate below 0.10 percent. Based on these empirical observations, it is not clear that one would need to impose a lower bound to model these data. As a consequence, we limit our focus to Gaussian models even for the U.K.

\section{Model Estimation and Results}

In this section, we first describe the flexible dynamic term structure model used in our analysis before we proceed to a brief summary of the estimation results.

\subsection{The AFGNS Model}

To motivate our model choice, we note that Gürkaynak et al. (2007) prefer the Svensson (1995) yield curve model over the simpler specification of Nelson and Siegel (1987) because 
it allows for an additional 'hump' that helps fit bond yields beyond the ten- to fifteen-year maturity spectrum. Building on this intuition we consider a generalized arbitrage-free NelsonSiegel (AFGNS) model introduced in Christensen et al. (2009) that includes an additional slope and curvature factor. In addition to theoretical consistency, this class of models provides us with a very accurate fit to the entire yield curve observed in the four government bond markets we examine. This is particularly important given our focus on understanding the pricing of very long bonds trading in these markets.

In the AFGNS class of models, the vector of state variables is $X_{t}=\left(L_{t}, S_{t}^{1}, S_{t}^{2}, C_{t}^{1}, C_{t}^{2}\right)$, while the instantaneous risk-free rate is defined by

$$
r_{t}=L_{t}+S_{t}^{1}+S_{t}^{2}
$$

To generate the appropriate Nelson and Siegel (1987) factor loading structure in the yield function, the risk-neutral (or $\mathbb{Q}$-) dynamics of the state variables are given by the stochastic differential equations

$$
\left(\begin{array}{l}
d L_{t} \\
d S_{t}^{1} \\
d S_{t}^{2} \\
d C_{t}^{1} \\
d C_{t}^{2}
\end{array}\right)=\left(\begin{array}{ccccc}
0 & 0 & 0 & 0 & 0 \\
0 & -\lambda_{1} & 0 & \lambda_{1} & 0 \\
0 & 0 & -\lambda_{2} & 0 & \lambda_{2} \\
0 & 0 & 0 & -\lambda_{1} & 0 \\
0 & 0 & 0 & 0 & -\lambda_{2}
\end{array}\right)\left(\begin{array}{c}
L_{t} \\
S_{t}^{1} \\
S_{t}^{2} \\
C_{t}^{1} \\
C_{t}^{2}
\end{array}\right) d t+\Sigma\left(\begin{array}{c}
d W_{t}^{L, \mathbb{Q}} \\
d W_{t}^{S^{1}, \mathbb{Q}} \\
d W_{t}^{S^{2}, \mathbb{Q}} \\
d W_{t}^{C^{1}, \mathbb{Q}} \\
d W_{t}^{C^{2}, \mathbb{Q}}
\end{array}\right), \quad \lambda_{1}>\lambda_{2}>0
$$

where we assume that $\Sigma$ is a diagonal matrix.

In this model, zero-coupon bond yields are given by

$$
y_{t}(\tau)=L_{t}+\frac{1-e^{-\lambda_{1} \tau}}{\lambda_{1} \tau} S_{t}^{1}+\frac{1-e^{-\lambda_{2} \tau}}{\lambda_{2} \tau} S_{t}^{2}+\left[\frac{1-e^{-\lambda_{1} \tau}}{\lambda_{1} \tau}-e^{-\lambda_{1} \tau}\right] C_{t}^{1}+\left[\frac{1-e^{-\lambda_{2} \tau}}{\lambda_{2} \tau}-e^{-\lambda_{2} \tau}\right] C_{t}^{2}-\frac{A(\tau)}{\tau},
$$

where $\frac{A(\tau)}{\tau}$ represents a yield-adjustment term that ensures absence of arbitrage, see Christensen et al. (2009) for details.

Now, the description of the model is completed by specifying the risk premiums that connect the factor dynamics under the $\mathbb{Q}$-measure to the dynamics under the real-world (or historical) $\mathbb{P}$-measure. To facilitate empirical implementation, we use the essentially affine risk premium specification introduced in Duffee (2002). In the Gaussian framework, this specification implies that the risk premiums $\Gamma_{t}$ take the following form

$$
\Gamma_{t}=\gamma^{0}+\gamma^{1} X_{t}
$$

where $\gamma^{0} \in \mathbf{R}^{5}$ and $\gamma^{1} \in \mathbf{R}^{5 \times 5}$ contain unrestricted parameters.

Thus, the resulting unrestricted five-factor AFGNS model has $\mathbb{P}$-dynamics given by 


$$
\left(\begin{array}{c}
d L_{t} \\
d S_{t}^{1} \\
d S_{t}^{2} \\
d C_{t}^{1} \\
d C_{t}^{2}
\end{array}\right)=\left(\begin{array}{ccccc}
\kappa_{11}^{\mathbb{P}} & \kappa_{12}^{\mathbb{P}} & \kappa_{13}^{\mathbb{P}} & \kappa_{14}^{\mathbb{P}} & \kappa_{15}^{\mathbb{P}} \\
\kappa_{21}^{\mathbb{P}} & \kappa_{22}^{\mathbb{P}} & \kappa_{23}^{\mathbb{P}} & \kappa_{24}^{\mathbb{P}} & \kappa_{25}^{\mathbb{P}} \\
\kappa_{31}^{\mathbb{P}} & \kappa_{32}^{\mathbb{P}} & \kappa_{33}^{\mathbb{P}} & \kappa_{34}^{\mathbb{P}} & \kappa_{35}^{\mathbb{P}} \\
\kappa_{41}^{\mathbb{P}} & \kappa_{42}^{\mathbb{P}} & \kappa_{43}^{\mathbb{P}} & \kappa_{44}^{\mathbb{P}} & \kappa_{45}^{\mathbb{P}} \\
\kappa_{51}^{\mathbb{P}} & \kappa_{52}^{\mathbb{P}} & \kappa_{53}^{\mathbb{P}} & \kappa_{54}^{\mathbb{P}} & \kappa_{55}^{\mathbb{P}}
\end{array}\right)\left(\left(\begin{array}{c}
\theta_{1}^{\mathbb{P}} \\
\theta_{2}^{\mathbb{P}} \\
\theta_{3}^{\mathbb{P}} \\
\theta_{4}^{\mathbb{P}} \\
\theta_{5}^{\mathbb{P}}
\end{array}\right)-\left(\begin{array}{c}
L_{t} \\
S_{t}^{1} \\
S_{t}^{2} \\
C_{t}^{1} \\
C_{t}^{2}
\end{array}\right)\right) d t+\Sigma\left(\begin{array}{c}
d W_{t}^{L, \mathbb{P}} \\
d W_{t}^{S^{1}, \mathbb{P}} \\
d W_{t}^{S^{2}, \mathbb{P}} \\
d W_{t}^{C^{1}, \mathbb{P}} \\
d W_{t}^{C^{2}, \mathbb{P}}
\end{array}\right)
$$

This is the transition equation in the Kalman filter estimation.

Estimation of this and related affine term structure models has typically been conducted on zero-coupon yields generated from the underlying government bond prices; such as by using a Svensson (1995) model as done in Gürkaynak et al. (2007) for the U.S. Treasury yield curve. In a recent paper, Andreasen et al. (2019, henceforth ACR) develop an estimation technique based on a "big data" approach using the underlying bond prices directly. They find that this one-step approach is more efficient and reduces estimation noise from the Svensson-type interpolation of yields. We therefore use the ACR estimation technique for our analysis.

To understand the ACR technique, consider the value at time $t$ of a fixed-coupon bond with maturity $\tau$ that pays a coupon $C$ annually. Its price, denoted $P_{t}^{c}(\tau, C)$, is simply the sum of its cash flow payments weighted by the zero-coupon bond price function $P_{t}(\tau):{ }^{8}$

$$
P_{t}^{c}(\tau, C)=C\left(t_{1}-t\right) P_{t}\left(t_{1}\right)+\sum_{j=2}^{N} C P_{t}\left(t_{j}\right)+P_{t}(\tau), \quad t<t_{1}<\ldots<t_{N}=\tau
$$

where $P_{t}(\tau)$ is given by $P_{t}(\tau)=\exp \left(-y_{t}(\tau) \tau\right)$, and $y_{t}(\tau)$ is given by equation $(2)$.

Due to the nonlinear relationship between the state variables and the bond prices, the model cannot be estimated with the standard Kalman filter. Instead, we use the extended Kalman filter as in Kim and Singleton (2012). Furthermore, to make the fitted errors comparable across bonds of various maturities, we follow ACR and scale each bond price by its duration, which is calculated before estimation. Thus, the measurement equation for the bond prices in the Kalman filter estimation is of the form

$$
\frac{P_{t}^{i}\left(\tau^{i}, C^{i}\right)}{D_{t}^{i}\left(\tau^{i}, C^{i}\right)}=\frac{\widehat{P}_{t}^{i}\left(\tau^{i}, C^{i}\right)}{D_{t}^{i}\left(\tau^{i}, C^{i}\right)}+\varepsilon_{t}^{i}
$$

where $\widehat{P}_{t}^{i}\left(\tau^{i}, C^{i}\right)$ is the model-implied price of bond $i$ and $D_{t}^{i}\left(\tau^{i}, C^{i}\right)$ is its duration, which is fixed and calculated before estimation. Finally, the error terms in the measurement and transition equations are assumed to be independent. Thus, the error structure is given by

$$
\left(\begin{array}{l}
\eta_{t} \\
\varepsilon_{t}
\end{array}\right) \sim N\left[\left(\begin{array}{l}
0 \\
0
\end{array}\right),\left(\begin{array}{cc}
Q & 0 \\
0 & H
\end{array}\right)\right]
$$

\footnotetext{
${ }^{8}$ This is the formula for the clean bond price that does not account for any accrued interest and maps to our bond price data.
} 


\begin{tabular}{c|cc|cc|cc|cc}
\hline \hline \multirow{2}{*}{ Parameter } & \multicolumn{2}{|c|}{ Austria } & \multicolumn{2}{c|}{ France } & \multicolumn{2}{c|}{ Switzerland } & \multicolumn{2}{c}{ U.K. } \\
\cline { 2 - 9 } & Est. & SE & Est. & SE & Est. & SE & Est. & SE \\
\hline$\kappa_{11}^{\mathbb{P}}$ & 0.0003 & 0.0008 & 0.0019 & 0.0049 & 0.0001 & 0.0037 & 0.0006 & 0.0040 \\
$\kappa_{22}^{\mathbb{P}}$ & 0.3603 & 0.2023 & 0.1956 & 0.1209 & 0.0599 & 0.0084 & 0.0003 & 0.0026 \\
$\kappa_{33}^{\mathbb{P}}$ & 0.1773 & 0.1769 & 0.1101 & 0.1013 & 0.0003 & 0.0127 & 0.0097 & 0.0051 \\
$\kappa_{44}^{\mathbb{P}}$ & 0.3394 & 0.2148 & 0.8856 & 0.1459 & 0.0001 & 0.0048 & 0.0097 & 0.0051 \\
$\kappa_{55}^{\mathbb{P}}$ & 0.2009 & 0.1363 & 0.3918 & 0.1242 & 0.0004 & 0.0119 & 0.0206 & 0.0059 \\
\hline$\sigma_{11}$ & 0.0007 & 0.0000 & 0.0021 & 0.0000 & 0.0020 & 0.0000 & 0.0022 & 0.0000 \\
$\sigma_{22}$ & 0.0103 & 0.0001 & 0.0104 & 0.0001 & 0.0336 & 0.0002 & 0.0163 & 0.0003 \\
$\sigma_{33}$ & 0.0083 & 0.0001 & 0.0099 & 0.0001 & 0.0061 & 0.0001 & 0.0108 & 0.0001 \\
$\sigma_{44}$ & 0.0152 & 0.0004 & 0.0197 & 0.0002 & 0.0348 & 0.0005 & 0.0262 & 0.0004 \\
$\sigma_{55}$ & 0.0173 & 0.0001 & 0.0219 & 0.0002 & 0.0160 & 0.0002 & 0.0423 & 0.0002 \\
\hline$\theta_{1}^{\mathbb{P}}$ & 0.0598 & 0.0182 & 0.0701 & 0.0142 & 0.0328 & 0.0142 & 0.0363 & 0.0091 \\
$\theta_{2}^{\mathbb{P}}$ & 0.0074 & 0.0109 & 0.0102 & 0.0157 & 0.1036 & 0.0310 & 0.1541 & 0.0047 \\
$\theta_{3}^{\mathbb{P}}$ & -0.0351 & 0.0160 & -0.0333 & 0.0168 & 0.0017 & 0.0291 & 0.0177 & 0.0074 \\
$\theta_{4}^{\mathbb{P}}$ & -0.0033 & 0.0162 & 0.0013 & 0.0058 & 0.1452 & 0.0280 & -0.0418 & 0.0051 \\
$\theta_{5}^{\mathbb{P}}$ & -0.0014 & 0.0196 & -0.0036 & 0.0136 & -0.0034 & 0.0275 & 0.1468 & 0.0075 \\
\hline$\lambda_{1}$ & 1.4008 & 0.0046 & 0.9387 & 0.0012 & 3.1142 & 0.0114 & 1.0867 & 0.0016 \\
$\lambda_{2}$ & 0.1502 & 0.0003 & 0.1685 & 0.0002 & 0.1682 & 0.0007 & 0.1260 & 0.0003 \\
\hline$\sigma_{\varepsilon}$ & 0.0005 & $3.1 \times 10^{-7}$ & 0.0003 & $1.7 \times 10^{-7}$ & 0.0007 & $4.5 \times 10^{-7}$ & 0.0006 & $2.3 \times 10^{-7}$ \\
\hline \hline
\end{tabular}

Table 1: Estimated Dynamic Parameters

The table shows the estimated dynamic parameters for the international panel of AFGNS models, each estimated with a diagonal specification of $K^{\mathbb{P}}$ and $\Sigma$.

where $H=\sigma_{\varepsilon}^{2} I$.

\subsection{Estimation Results}

In this section, we briefly summarize the estimation results of the AFGNS model applied to the four government bond markets in our sample.

Table 1 reports the estimated dynamic parameters. We note that we do see variations across markets, which should be expected given that both the sample period and cross sectional coverage vary from country to country. This affects the estimated persistence of the five state variables as well as their estimated volatilities. It also impacts the value of $\lambda_{1}$ in particular given that it determines the rate of decay in the yield factor loading of the shorterterm slope factor in the model; a high value of this parameter implies a rapid decay of this factor and suggests that the estimated model puts much emphasis on fitting the short end of the yield curve. In contrast, the estimated values of the second decay parameter $\lambda_{2}$ are relatively close to each other. This implies that the peak of the hump for the second curvature factor is located near the same maturity point in all four markets.

Table 2 reports the summary statistics for the fit to all bonds in the sample from the four model estimations broken down into maturity buckets. Also reported are the number of fitted errors observed in each maturity bucket in each market. In general, we note the very 


\begin{tabular}{|c|c|c|c|c|c|c|c|c|c|c|c|c|}
\hline \multirow{2}{*}{$\begin{array}{c}\text { Maturity } \\
\text { bucket }\end{array}$} & \multicolumn{3}{|c|}{ Austria } & \multicolumn{3}{|c|}{ France } & \multicolumn{3}{|c|}{ Switzerland } & \multicolumn{3}{|c|}{ U.K. } \\
\hline & No. obs. & Mean & RMSE & No. obs. & Mean & RMSE & No. obs. & Mean & RMSE & No. obs. & Mean & RMSE \\
\hline $0-2$ & 33,658 & -3.18 & 8.76 & 39,051 & -0.99 & 4.70 & 17,212 & -0.28 & 9.39 & 21,209 & -0.15 & 4.68 \\
\hline $2-4$ & 31,170 & 3.18 & 6.35 & 38,996 & 1.68 & 4.10 & 20,127 & 0.56 & 7.58 & 38,353 & 0.18 & 5.06 \\
\hline $4-6$ & 22,852 & 4.03 & 7.41 & 30,679 & 2.77 & 4.83 & 20,302 & -0.74 & 6.87 & 37,101 & -0.30 & 6.25 \\
\hline $6-8$ & 17,022 & 4.68 & 7.71 & 21,259 & 2.57 & 5.41 & 18,393 & -0.39 & 6.03 & 26,606 & -0.59 & 6.51 \\
\hline $8-10$ & 13,713 & 5.23 & 7.31 & 22,837 & 4.67 & 6.52 & 16,967 & -0.68 & 4.12 & 24,216 & -0.05 & 5.36 \\
\hline $10-12$ & 5,264 & 4.72 & 6.40 & 7,007 & 4.45 & 5.42 & 13,046 & -0.67 & 4.29 & 14,458 & -0.76 & 4.56 \\
\hline $12-14$ & 3,289 & 7.78 & 8.91 & 5,377 & 4.03 & 5.21 & 7,908 & 0.43 & 4.15 & 9,140 & 0.45 & 3.55 \\
\hline $14-16$ & 2,911 & 7.08 & 7.98 & 5,874 & 4.24 & 6.50 & 4,872 & 2.01 & 5.78 & 8,188 & 0.99 & 3.35 \\
\hline $16-18$ & 1,708 & 5.29 & 7.94 & 2,365 & 2.38 & 5.97 & 4,407 & 1.51 & 3.99 & 7,739 & -0.75 & 3.36 \\
\hline $18-20$ & 1,617 & 4.85 & 10.34 & 3,155 & 0.84 & 5.85 & 4,841 & 1.46 & 6.00 & 7,877 & -0.17 & 2.93 \\
\hline $20-22$ & 1,338 & 2.38 & 6.53 & 3,080 & 3.11 & 8.18 & 2,673 & -0.21 & 3.76 & 7,282 & 0.37 & 2.76 \\
\hline $22-24$ & 1,182 & 4.49 & 6.12 & 2,716 & 4.36 & 7.69 & 3,017 & -2.40 & 4.85 & 6,155 & 0.43 & 3.48 \\
\hline $24-26$ & 1,565 & 3.37 & 8.44 & 3,025 & 5.65 & 8.26 & 2,661 & -3.04 & 6.56 & 5,665 & -0.16 & 3.08 \\
\hline $26-28$ & 2,052 & 3.87 & 9.81 & 3,286 & 5.80 & 8.14 & 2,493 & -6.83 & 8.52 & 5,598 & 0.52 & 2.82 \\
\hline $28-30$ & 1,699 & 1.44 & 7.50 & 3,811 & 4.88 & 7.86 & 2,310 & -5.60 & 7.85 & 6,581 & 0.05 & 2.89 \\
\hline $30<$ & 5,398 & 1.54 & 6.12 & 11,332 & 4.25 & 6.04 & 8,487 & 0.17 & 6.37 & 26,053 & -0.32 & 3.36 \\
\hline All bonds & 146,381 & 2.43 & 7.62 & 203,817 & 2.37 & 5.45 & 149,634 & -0.36 & 6.47 & 252,089 & -0.12 & 4.86 \\
\hline
\end{tabular}

Table 2: Summary Statistics of Fitted Errors of Government Bond Yields

This table reports the mean pricing errors (Mean) and the root mean-squared pricing errors (RMSE) of government bond prices for the international panel of AFGNS models, each estimated with a diagonal specification of $K^{\mathbb{P}}$ and $\Sigma$. The pricing errors are reported in basis points and computed as the difference between the implied yield on the coupon bond and the model-implied yield on this bond. Each data sample is daily and described in Section 2.

strong fit of the AFGNS model to the entire yield curve in each of the four government bond markets. This demonstrates that the model is able to produce the very accurate fit required to give us confidence in our assessment of the costs of issuing 50-year bonds in these four markets. Of particular relevance to our exercise we note that the AFGNS model is able to fit the prices of bonds with more than 30 years to maturity about as accurately as those of other medium- and long-term bonds.

\section{Assessment of the Costs of Issuing 50-Year Bonds}

In this section, we assess the costs of issuing 50-year bonds. However, as outlined in the introduction, we are going to narrow the issuing decision to a single choice that we consider to be particularly realistic and relevant for the question at hand: Should the U.S. government issue a 50-year bond as an alternative to raising the same amount by issuing one of its regular 30-year Treasury bonds? To provide an answer, we first examine the evidence from our international panel of government bond prices before we attempt to offer a quantification of this cost based on long-term yield extrapolations rooted in U.S. Treasury yield data as described in Christensen et al. (2021). We end the section with a brief summary of our results and findings. 


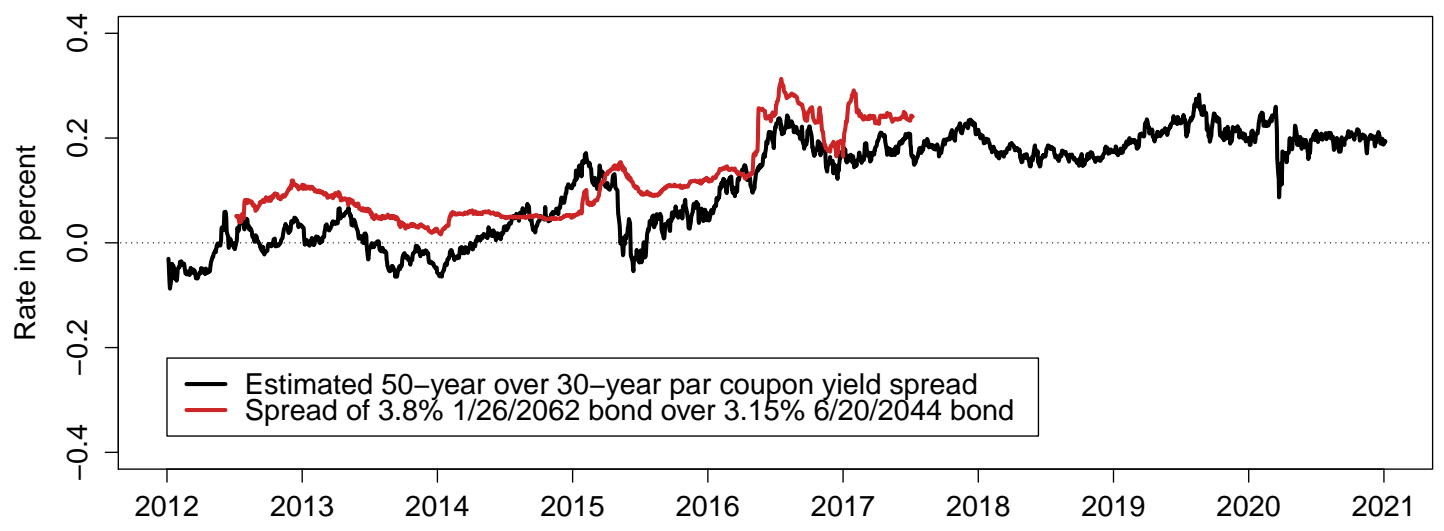

Figure 9: Austrian 50-Over-30 Year Par Yield Spreads

\subsection{Evidence from an International Panel}

In this section, we use our international panel of estimated AFGNS models to calculate fitted par yields at integer maturities for each of the four countries in our panel. We then focus on the spread between the fitted 50-year par yield and the fitted 30-year par yield, which we refer to as the 50-over-30 year par yield spread. Given that the U.S. government issues Treasury notes and bonds close to par, ${ }^{9}$ this spread represents an empirical proxy of the excess costs issuance of a 50-year bond would entail instead of issuing a 30-year bond.

\subsubsection{Analysis of Austrian Data}

Figure 9 shows the 50-over-30 year par yield spread implied by the AFGNS model estimated based on the Austrian government bond data. The shown data starts in 2012 when the Austrian government issued its first 50-year bond. To verify the accuracy of our synthetic model-implied cost measure, we also plot the directly observable yield spread between the 50year bond (3.8\% 1/26/2062) and the 30-year bond (3.15\% 6/20/2044) issued around the same time as discussed in Section 2.1. ${ }^{10}$ We stress that this observable measure only represents an approximation to the excess costs of the 50-year bond because the maturity difference is not exactly 20 years. Furthermore, as time passes, the 50-year bond no longer has 50 years to maturity, which explains why we only plot this series for the first five years of its trading. Finally, the two bonds have different coupon rates, which may affect the cost assessment over time depending on the shape of the yield curve. Our synthetic measure based on modelimplied fixed-maturity par yields is not plagued by any of these issues. It is based on par yields

\footnotetext{
${ }^{9}$ That is, the coupon rate offered at the initial auction is adjusted in 12.5 basis point increments to ensure that the achieved auction price is very close to par.

${ }^{10}$ For each bond, we convert the mid-market price into yield to maturity and plot the difference.
} 


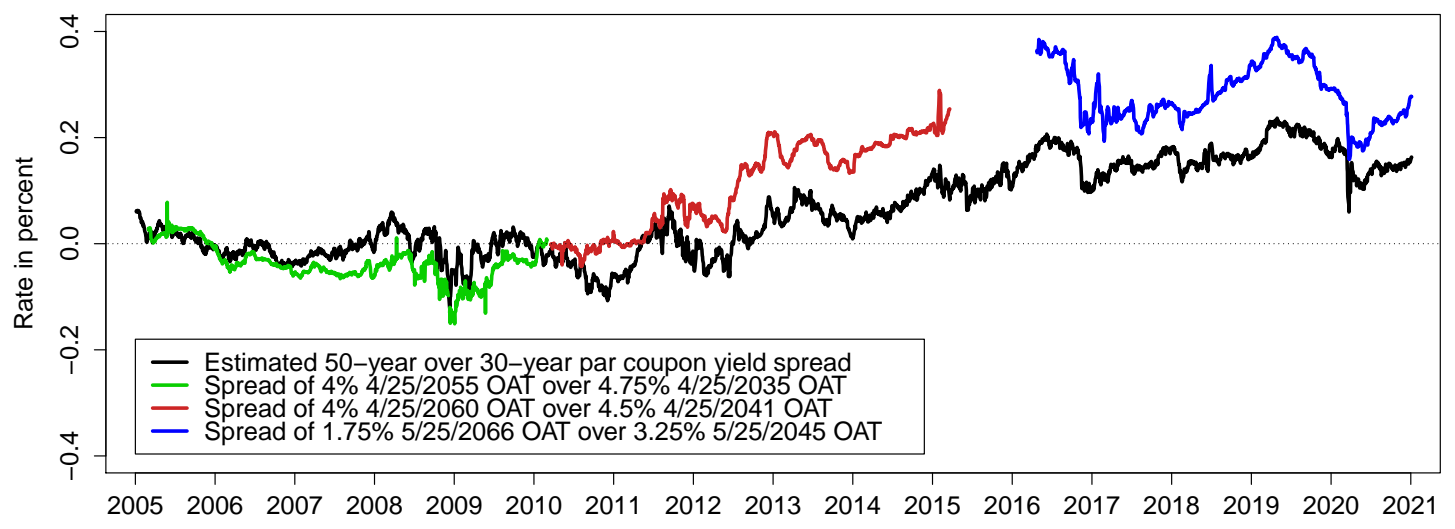

Figure 10: French 50-Over-30 Year Par Yield Spreads

for every observation date. The maturities used are exactly 30 and 50 years by construction and hence constant over time. And the bond price formulas directly takes variation in the shape of the yield curve into account. That said, it is comforting to see the very high positive correlation between our synthetic cost measure and the observable proxy for the overlapping period.

For the shown period our synthetic cost measure implied by the Austrian data averages 11.97 basis points with a mild upward trend that leaves it close to 20 basis points by the end of 2020 .

\subsubsection{Analysis of French Data}

Turning to the French data, Figure 10 shows the 50-over-30 year par yield spread implied by the AFGNS model estimated based on the French government bond data. The shown data starts in 2005 when the French government issued its first 50-year bond. Given that the French government has issued a total of three 50-year bonds during our sample period in addition to repeated issuance of 30-year bonds every two or three years, we can construct three observable proxies to our synthetic cost measure. As before, we only track each of these observable proxies for the first five years of trading, while they represent a close approximation to our desired cost measure. The closeness of the proxies to our synthetic measure again provides support for our approach.

In terms of time series profile, our synthetic cost measure derived from the French bond data is highly correlated with the series implied by the Austrian bond data. For the overlapping period the correlation is 88 percent. This suggests that long-term bonds are priced very similarly across core government bond markets in the euro area as one could anticipate. For the entire shown period our synthetic cost measure implied by the French data averages 6.11 


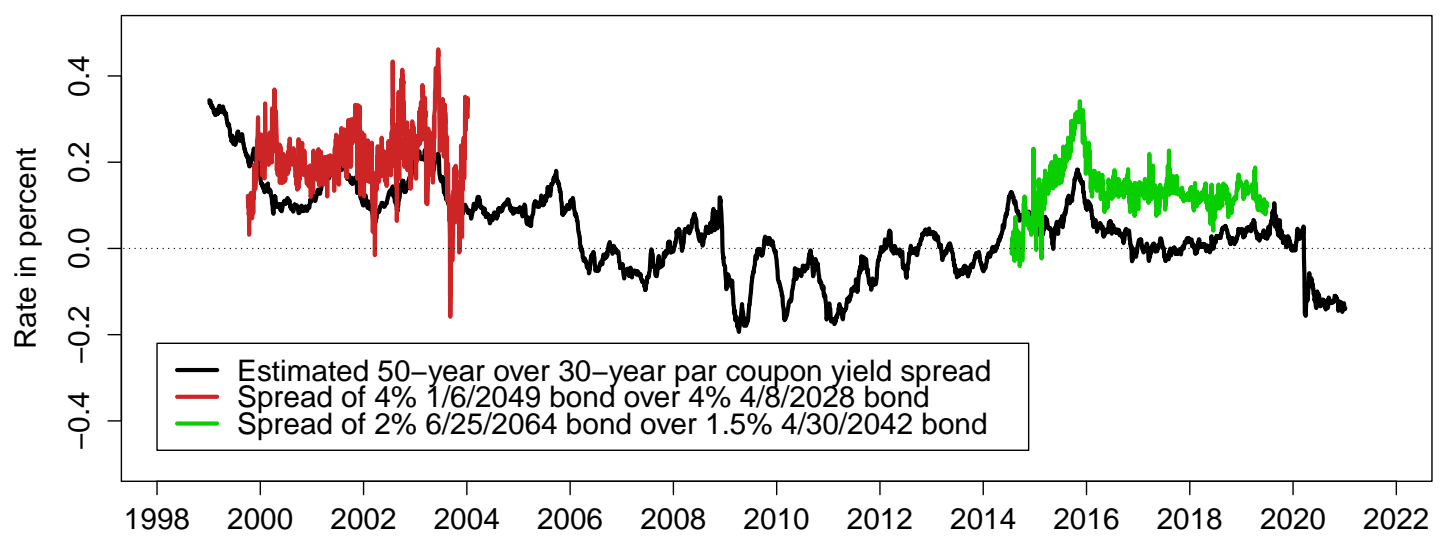

Figure 11: Swiss 50-Over-30 Year Par Yield Spreads

basis points with a mild upward trend that leaves it close to 10 basis points by the end of 2020.

\subsubsection{Analysis of Swiss Data}

Figure 11 shows the 50-over-30 year par yield spread implied by the AFGNS model estimated based on the Swiss government bond data. The shown data starts in 1999 when the Swiss government issued its first 50-year bond. In this case, we have two observable proxies for our synthetic cost measure derived from the two Swiss 50-year bonds and two 30-year bonds issued close to the same time. As before, we only track these observable proxies during the first five years of their trading when they are most relevant as approximations to our ideal cost measure. Still, we stress the closeness and high correlation with our synthetic cost measure during the overlapping periods.

Interestingly, in the Swiss data, there is a clear downward trend in our synthetic cost measure. It starts out above 30 basis points in 1999 and ends below -10 basis points by the end of 2020. For the entire period it averages 3.93 basis points. Thus, the Swiss government appears to face almost no tradeoff in terms of pricing between issuing 30- and 50-year bonds.

\subsubsection{Analysis of U.K. Data}

Finally, we examine the results from our U.K. data. Figure 12 shows the 50-over-30 year par yield spread implied by the AFGNS model estimated based on the U.K. government bond data. The shown data starts in 2005 when the U.K. government issued its first 50-year bond. As in the French data, we can construct three observable proxies to our synthetic cost measure, and all three series track our synthetic measure very closely. Thus, our approach 


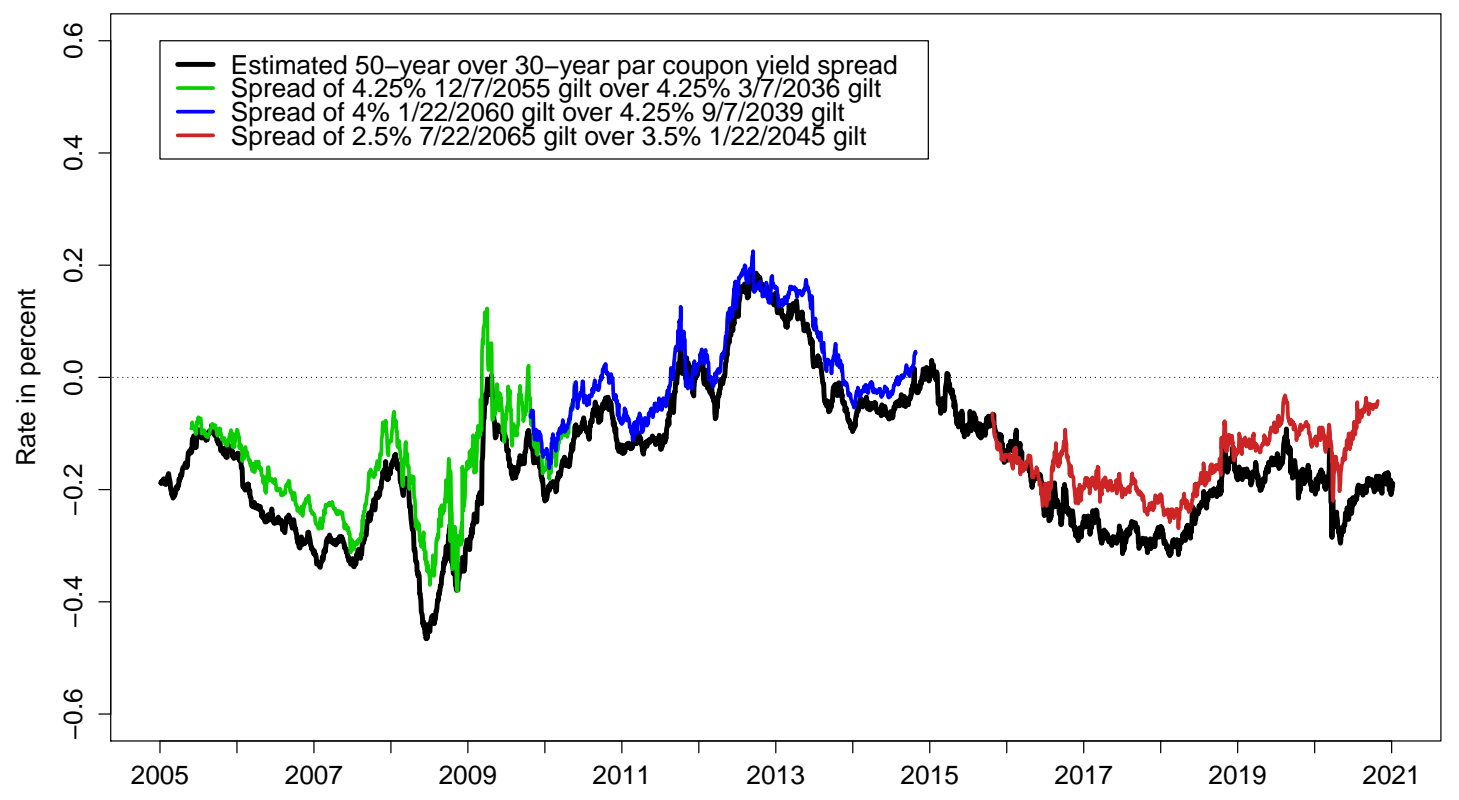

Figure 12: U.K. 50-Over-30 Year Par Yield Spreads

appears to be particularly accurate for the U.K. data.

Another interesting feature of the U.K. series is that it is mostly negative, meaning that the U.K. government has tended to be able to issue 50-year gilts at yields below those of newly issued 30-year gilts. Indeed, our synthetic cost measure has averaged -15.16 basis points since the first 50-year gilt was issued back in 2005. As a consequence, greater issuance of very long-term debt seems to be particularly recommendable for the U.K. government.

\subsubsection{Market Response to Launch of 50-Year Bonds}

In this section, we examine whether the introduction of 50-year bonds in the four bond markets in our international panel had any notable impact on the pricing of the existing established long bonds in these markets.

To do so, we focus on the 20- over 10-year par yield spread and the 30- over 10-year par yield spread implied by the four estimated AFGNS models. Given that we are interested in the market movements around the time of the issuance of the first 50-year bond, we start to track these two spread series two years before the introduction and end the analysis two years after it. These series are plotted for Austria and France in Figure 13, while the corresponding series for Switzerland and the U.K. are shown in Figure 14.

The main takeaway from these figures is that the launch of 50-year bond series in these markets appear to have had at most modest impacts on the relative pricing of existing 10- 


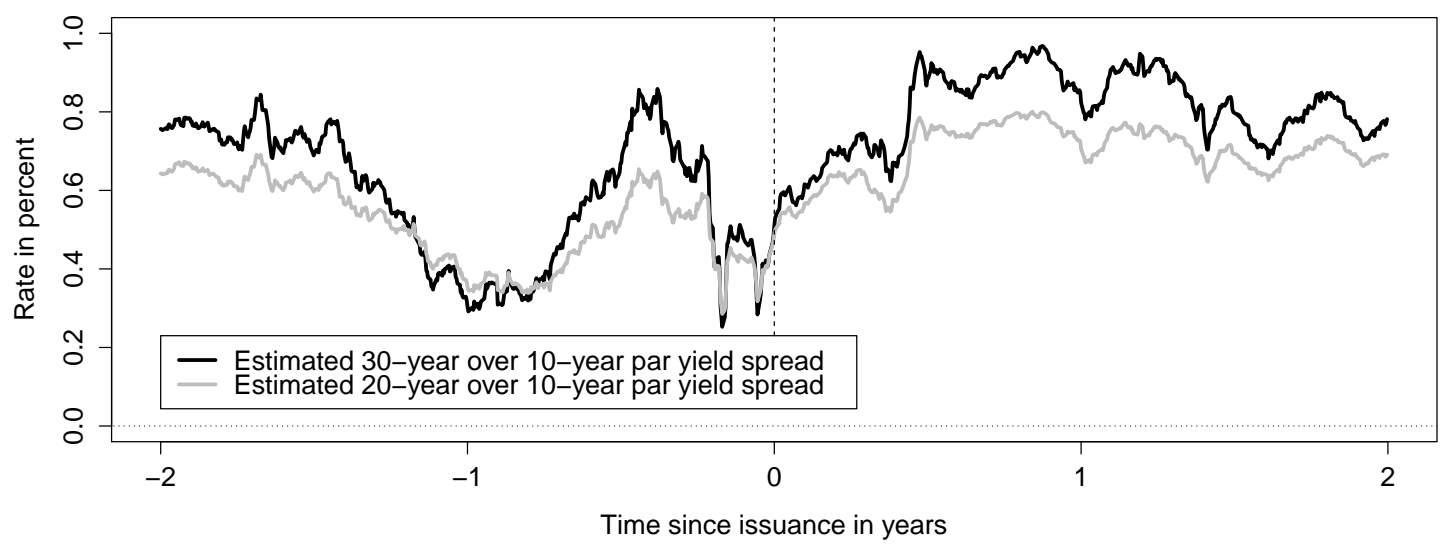

(a) Austria

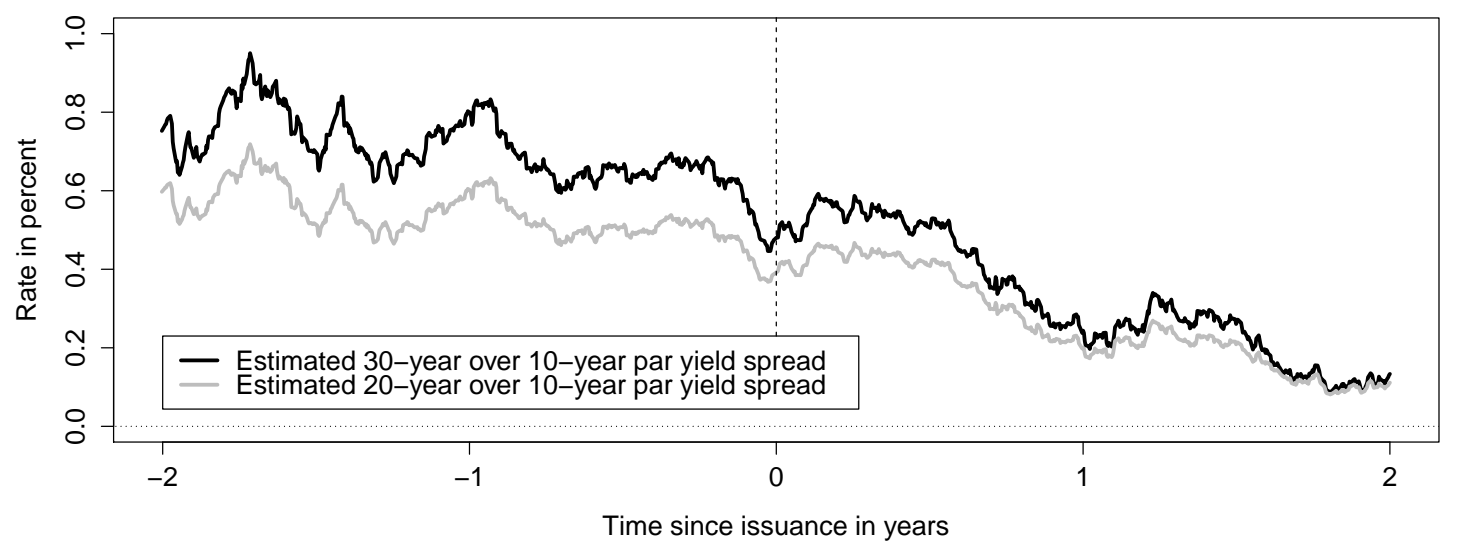

(b) France

Figure 13: Austrian and French Bond Market Impact of 50-Year Bond Introduction

to 30-year bonds. Overall, this seems like a reasonable outcome given that there is no new information received by the market from this decision by the government debt manager beyond getting a sense of the demand for very long-term bonds among the investors in the market.

\subsubsection{Bid-Ask Spreads of Long Bonds}

For Austria, France, and Switzerland we have bid-ask spreads available. For Austria and France these data are from Bloomberg and start in May 2011, while the Swiss data are provided by staff at the Swiss National Bank and start in 1998. This allows us to compare the bid-ask spreads in our pairs of 30- and 50-year bonds issued in these three countries with the exception of the first French bond pair issued back in 2005. As before, we track the data for each pair up to five years after the issuance of the pair's 50-year bond.

In Figure 15, the top panel shows the bid-ask spread comparison for our Austrian pair 


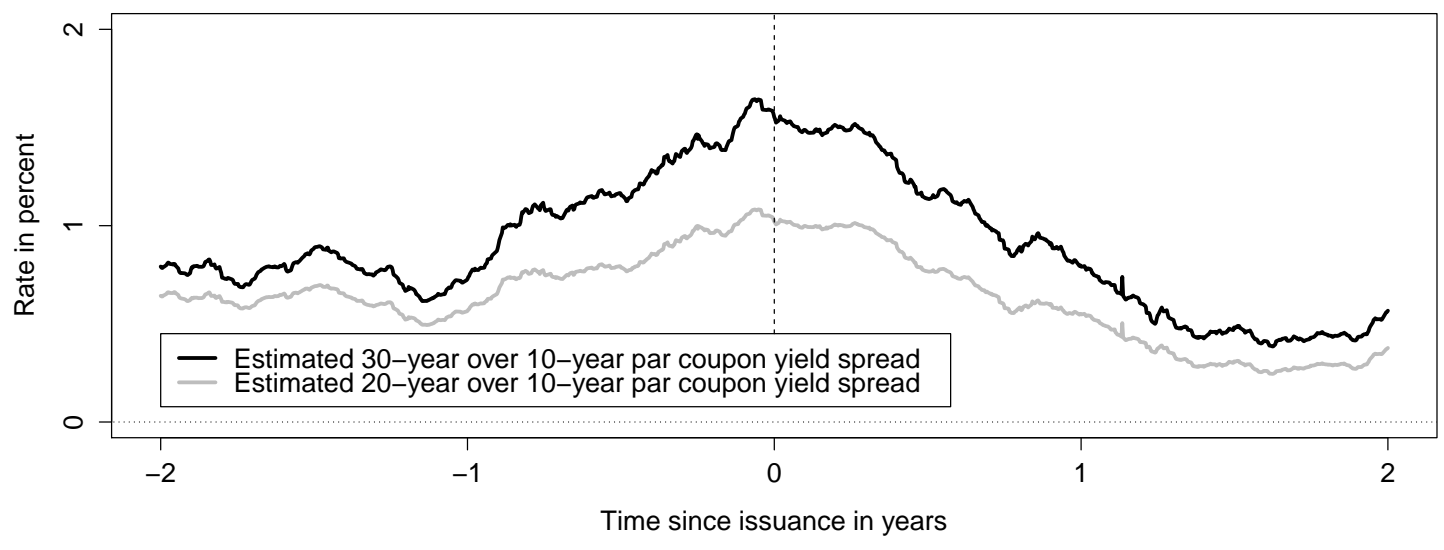

(a) Switzerland

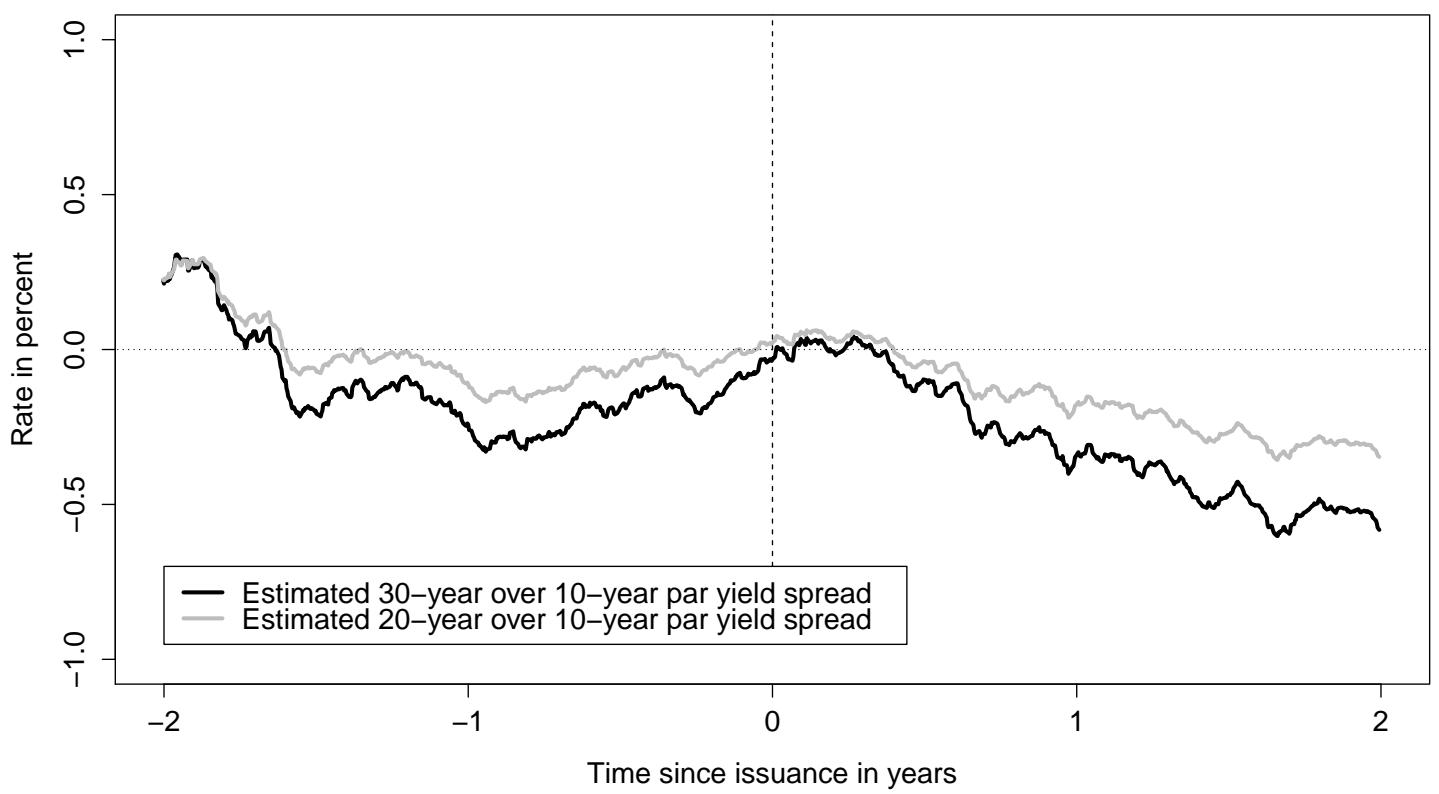

(b) U.K.

Figure 14: Swiss and U.K. Bond Market Impact of 50-Year Bond Introduction

of such bonds, while the middle panel shows the available data for the two most recent French pairs. Finally, the bottom panel contains the bid-ask spread series for our two Swiss bond pairs. Comparing the data across markets we note that bid-ask spreads of long bonds in the French government bond market are close to one basis point during normal market conditions. Much the same applies to Austrian government bonds, although their bid-ask spreads are slightly higher on average, which might be explained by the smaller size of that market. Finally, long bonds in the Swiss government bond markets have bid-ask spreads that are an order of magnitude higher than those observed in their euro area counterparts. This 


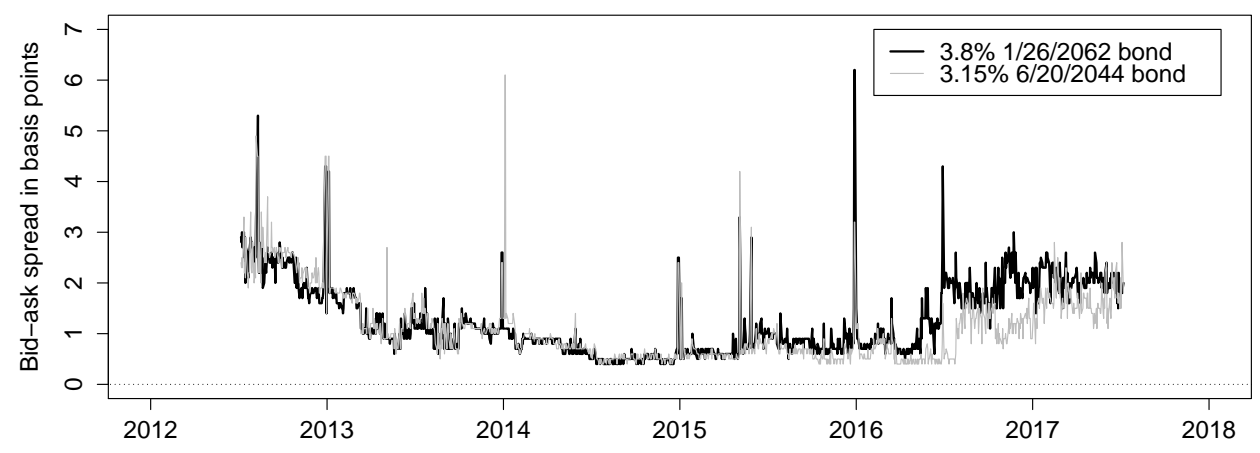

(a) Austria

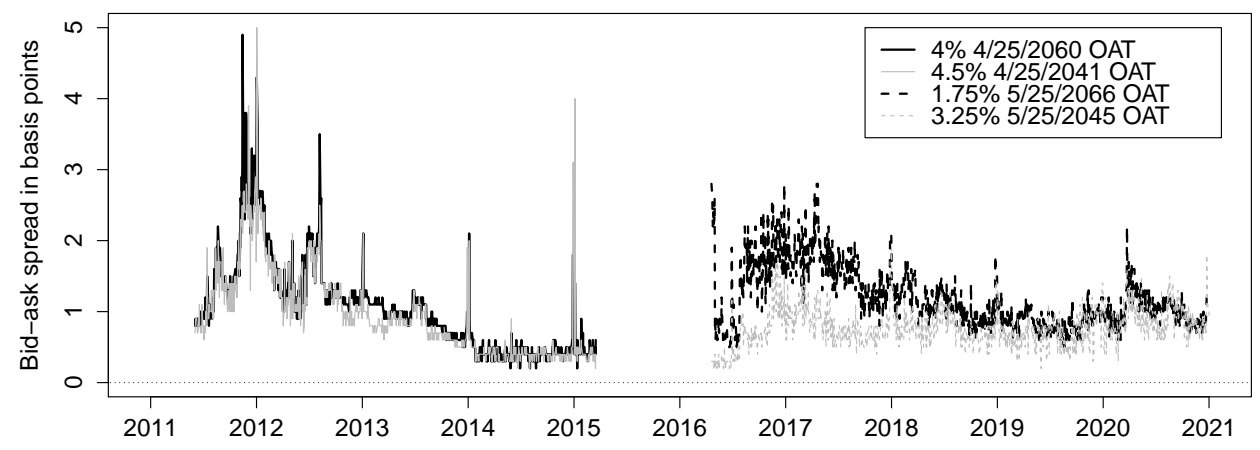

(b) France

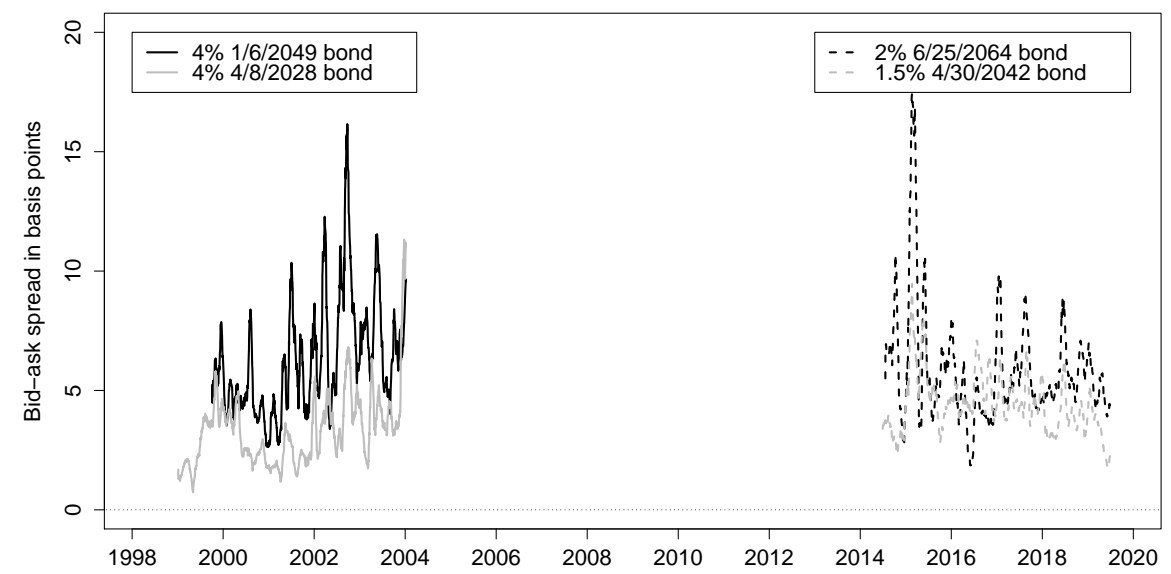

(c) Switzerland

Figure 15: Bid-Ask Spreads of 30-Year and 50-Year Bonds

is consistent with the point made by Christensen and Mirkov (2021) that Swiss government bonds are not particularly liquid. 
Now, we turn to the important comparison of the bid-ask spread of the bonds in each of our pairs. For the Austrian pair, there is a barely a difference between the two series during the first three years of trading after the issuance of the 50-year bond. The same applies to the second French bond pair with data shown for the 2011-2015 period, while there is a detectable, but small difference in bid-ask spreads for the last French bond pair. Finally, for the Swiss bond pairs, we do see a wedge in the bid-ask spreads favoring the 30-year bonds over the 50-year bonds based on this measure of current trading conditions.

Overall, the current bond market liquidity for 50-year bonds as measured by bid-ask spreads does seem to be somewhat below that of 30-year bonds, but not by a wide margin, and as documented earlier, this does not seem to be reflected in the pricing of the 50-year bonds in any particularly disadvantageous way.

To end the analysis of our international panel, we find the cost tradeoff of issuing 50-year bonds as a complement to conventional issuance of 30-year bonds to be favorable. Furthermore, the introduction itself of such long bonds does not seem to give rise to any detectable repricing in the existing part of the government bond yield curve. Finally, the trading costs of such long debt appears to be only marginally higher than those of 30-year bonds. As a consequence, the trading activity in the existing 30-year segment of the market is likely to be a useful guide for the expected secondary market trading of any new long bond series, which is presumably what prospective investors in these bonds are likely to care about.

\subsection{Evidence from Extrapolations Based on U.S. Data}

In this section, we generate extrapolations of 50-year par yields in the U.S. based on observed Treasury yields with maturities up to 30 year.

To begin, we first detail our U.S. Treasury yield data before we proceed to the results. Unlike the data for the other countries, our analysis of the U.S. Treasury yield curve is not based on individual bond prices. Instead, the specific Treasury yields used are synthetic zerocoupon yields constructed by the method described in Gürkaynak at al. (2007). The Treasury yields used have the following eleven maturities: three-month, six-month, one-year, two-year, three-year, five-year, seven-year, ten-year, fifteen-year, twenty-year, and thirty-year. ${ }^{11}$ The sample is limited to weekly observations over the period from January 8, 1995, to December 31, 2020. Figure 16 illustrates the time series of the three-month, two-year, five-year, tenyear, and thirty-year Treasury zero-coupon yields. Although short- and medium-term U.S. Treasury yields were constrained at times by the zero lower bound during the period from December 2008 to December 2015 when the Fed kept its target overnight federal funds rate in the range between 0 and $0.25 \%$, Christensen and Rudebusch (2016) only report fairly modest gains from using a shadow-rate modeling approach to account for the asymmetric

\footnotetext{
${ }^{11}$ The Board of Governors in Washington D.C. updates the factors and parameters of this method daily, see also the related website http://www.federalreserve.gov/pubs/feds/2006/index.html
} 


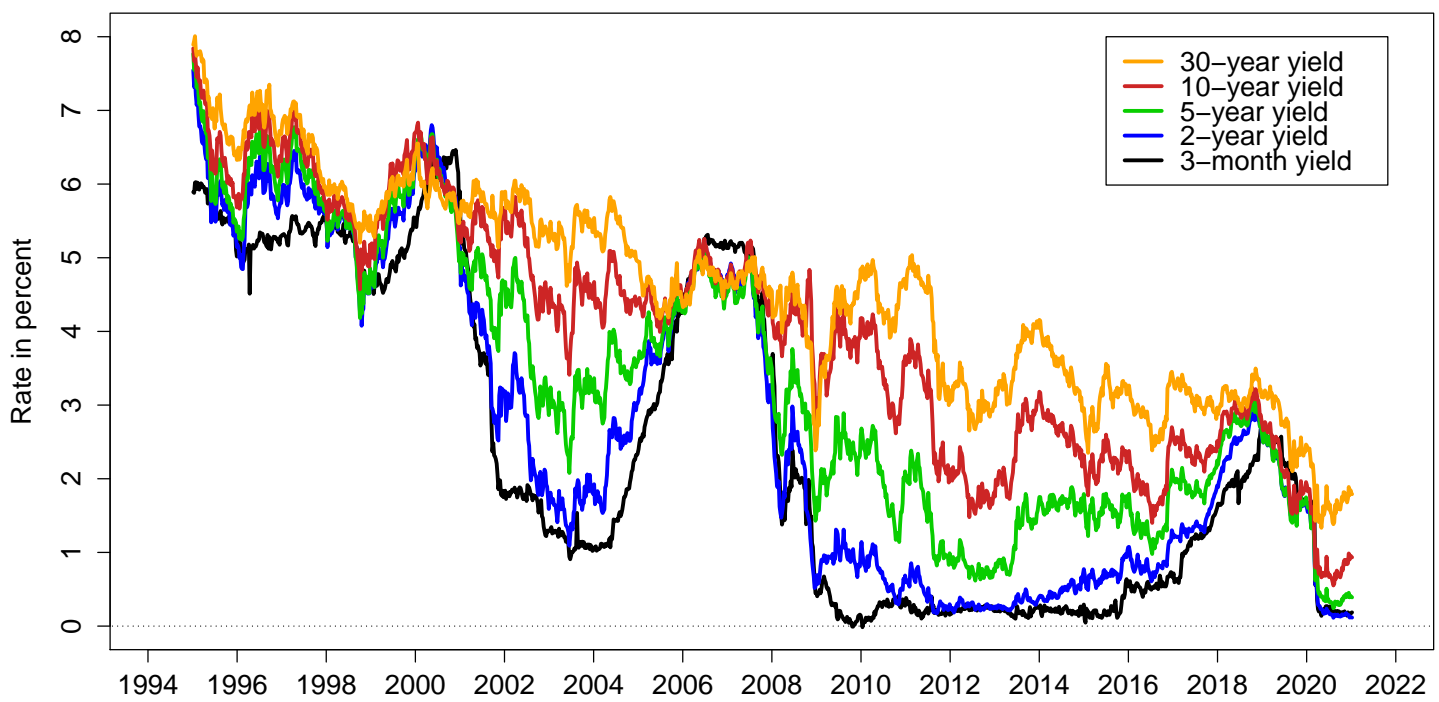

Figure 16: Time Series of U.S. Treasury Bond Yields

Illustration of the weekly U.S. Treasury zero-coupon bond yields covering the period from January 8, 1995, to December 31, 2020. The yields shown have maturities: three-month, two-year, five-year, ten-year and thirty-year.

yield behavior during this period. Based on this evidence, we choose to proceed with a Gaussian model even for this data.

In this case, we follow Christensen et al. (2021) and focus on the Nelson and Siegel (1987) yield curve model, which assumes that zero-coupon bond yields are functions of the term to maturity $\tau$ :

$$
y(\tau)=\beta_{1}+\beta_{2}\left(\frac{1-e^{-\lambda \tau}}{\lambda \tau}\right)+\beta_{3}\left(\frac{1-e^{-\lambda \tau}}{\lambda \tau}-e^{-\lambda \tau}\right),
$$

where $\beta_{1}, \beta_{2}, \beta_{3}$, and $\lambda$ are parameters. As argued by Diebold and Li (2006), the $\beta$ parameters can be interpreted as level, slope, and curvature factors, respectively, while $\lambda$ determines the maturity at which the peak sensitivity to the curvature factor is located.

Once the model is viewed as a factor model, we are only a small step away from imposing a dynamic structure on the three $\beta$ factors, as per Diebold et al. (2006). The dynamic version of the model is

$$
y_{t}(\tau)=L_{t}+S_{t}\left(\frac{1-e^{-\lambda \tau}}{\lambda \tau}\right)+C_{t}\left(\frac{1-e^{-\lambda \tau}}{\lambda \tau}-e^{-\lambda \tau}\right)
$$

where the factors $L_{t}, S_{t}$, and $C_{t}$ replace the $\beta$ parameters. The factor dynamics are assumed 


\begin{tabular}{c|cc}
\hline \hline Par. & Est. & SE \\
\hline$a_{11}$ & 0.9719 & 0.0194 \\
$a_{12}$ & 0.0181 & 0.0251 \\
$a_{13}$ & 0.0027 & 0.0156 \\
$a_{21}$ & -0.0213 & 0.0245 \\
$a_{22}$ & 0.9277 & 0.0255 \\
$a_{23}$ & 0.0532 & 0.0169 \\
$a_{31}$ & 0.0302 & 0.0729 \\
$a_{32}$ & 0.0308 & 0.0402 \\
$a_{33}$ & 0.9343 & 0.0295 \\
\hline$\mu_{1}$ & 0.0540 & 0.0077 \\
$\mu_{2}$ & -0.0231 & 0.0173 \\
$\mu_{3}$ & -0.0187 & 0.0202 \\
\hline$q_{11}$ & 0.0031 & 0.0001 \\
$q_{21}$ & -0.0032 & 0.0002 \\
$q_{22}$ & 0.0017 & 0.0001 \\
$q_{31}$ & -0.0021 & 0.0004 \\
$q_{32}$ & -0.0010 & 0.0005 \\
$q_{33}$ & 0.0080 & 0.0003 \\
\hline$\lambda$ & 0.4964 & 0.0039 \\
\hline$\sigma_{\varepsilon}$ & 0.0006 & $6 \times 10^{-6}$ \\
\hline \hline
\end{tabular}

Table 3: Estimated Dynamic Parameters for DNS Model of U.S. Treasury Yields The table shows the estimated dynamic parameters for the DNS model of U.S. Treasury yields estimated on samples with varying maximum bond maturity.

to have the following affine structure:

$$
\left(\begin{array}{c}
L_{t}-\mu_{L} \\
S_{t}-\mu_{S} \\
C_{t}-\mu_{C}
\end{array}\right)=\left(\begin{array}{lll}
a_{11} & a_{12} & a_{13} \\
a_{21} & a_{22} & a_{23} \\
a_{31} & a_{32} & a_{33}
\end{array}\right)\left(\begin{array}{c}
L_{t-1}-\mu_{L} \\
S_{t-1}-\mu_{S} \\
C_{t-1}-\mu_{C}
\end{array}\right)+\left(\begin{array}{c}
\eta_{t}(L) \\
\eta_{t}(S) \\
\eta_{t}(C)
\end{array}\right) .
$$

The error terms are assumed to be Gaussian and to have a full covariance matrix $Q$, which is made to be positive definite by imposing the Choleski decomposition $Q=q q^{\prime}$ with $q$ being a lower triangular matrix. Note that this choice is without loss of generality.

Given that our U.S. data consist of standard synthetic zero-coupon bond yields, the estimation of this dynamic Nelson-Siegel (DNS) model proceeds in the traditional way based on the standard Kalman filter unlike our estimation of the AFGNS models based on bond prices, which required the extended Kalman filter.

The estimated dynamic parameters are reported in Table 3 and close to those reported by Christensen et al. (2021) for their sample of U.S. Treasury yields.

As in our international panel analysis, we use the estimated DNS model to calculate par yields at integer maturities. Figure 17 shows the 50-over-30 year par yield spread extrapolated based on the estimated DNS model. We note that this extrapolated cost measure is mostly positive fluctuating in the range between 0 and 20 basis points with pronounced business cycle variation. In particular, the measure is near zero when the U.S. Treasury yield curve is 


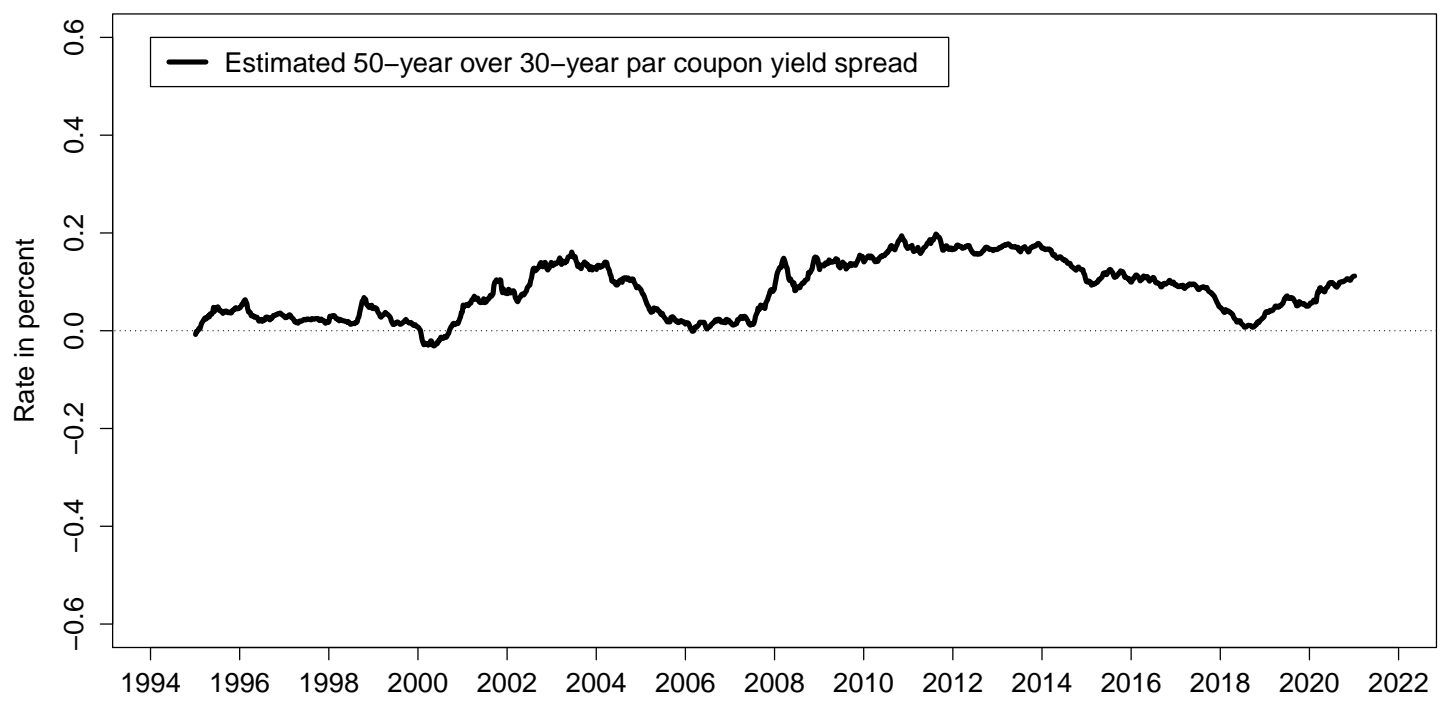

Figure 17: 50-Over-30 Year Yield Spreads Extrapolated from U.S. Treasury Yields

flat or outright inverted and close to its maximum value near 20 basis points when the U.S. Treasury yield curve is steep. For the entire 26-year period our extrapolated synthetic cost measure averages 8.37 basis points with a maximum of 19.78 basis points.

\subsection{Summary}

To summarize our results, we stress that there is little evidence to suggest that the excess costs of issuing 50-year bonds instead of a 30-year bond would go beyond 20 basis points, or 0.2 percent. Indeed, evidence both from an international panel of government bond prices where such long-term bonds have been issued and are trading and from extrapolations based on U.S. Treasury yield data suggests that the costs are likely to be lower and at times even negative (when the yield curve is flat or slightly inverted).

We add that the governments in our international panel have actually issued 50-year bonds in recent years with coupon rates around $1.5 \%$ to $2 \%$. Thus, these are not hypothetical numbers, but realistic funding costs for the U.S. government, in particular if natural real rates around the world continue to remain historically low, see Christensen and Rudebusch (2019). This could be a tool to help savers earn a positive interest rate in the current low-rate environment and to benefit the U.S government by locking in those low rates for 50 years. 


\section{Conclusion}

In this paper, we assess the cost to the U.S. Treasury of extending the maximum maturity of its issued debt from 30 years to 50 years. In one approach, we examine the international evidence from four established government bond markets where such long bonds are already trading. The results reveal a cost difference that tends to be less than 20 basis points, and even negative in some markets. In another approach, we follow Christensen et al. (2021) and rely on yield curve extrapolations rooted in a dynamic yield curve model estimated using U.S. Treasury yield data. The results are very similar and produce yield differences between zero and 20 basis points with a procyclical dynamic profile. Taken together these findings suggest that the proposed extension in the maximum maturity of debt issued by the U.S. government is likely to be very cost efficient as a complement to issuing conventional 30-year bonds.

In addition to improving the ability of pension funds and insurance companies to manage interest rate risk of long-dated assets and liabilities, issuance and subsequent secondary market trading of very long-lived bonds may also be helpful for evaluating the funding status of, or changes to, state-sponsored pension plans, including the U.S. social security system, as discussed in Bazelon and Smetters (1999) and Novy-Marx and Rauh (2009). Furthermore, prices of such bonds may serve as an important input for cost-benefit analysis of really longterm risks such as those tied to climate change or changing demographics as demonstrated

by Bauer and Rudebusch (2020). However, we leave those and other applications for future research. 


\section{References}

Andreasen, Martin M., Jens H. E. Christensen, and Glenn D. Rudebusch, 2019, "Term Structure Analysis with Big Data: One-Step Estimation Using Bond Prices," Journal of Econometrics, Vol. 212, 26-46.

Andreasen, Martin M. and Andrew Meldrum, 2019, "A Shadow Rate or a Quadratic Policy Rule? The Best Way to Enforce the Zero Lower Bound in the United States," Journal of Financial and Quantitative Analysis, Vol. 54, No. 5, 2261-2292.

Arellano, Christina and Ananth Ramanarayanan, 2012, "Default and the Maturity Structure in Sovereign Bonds," Journal of Political Economy, Vol. 120, No. 2, 187-232.

Bauer, Michael D., and Glenn D. Rudebusch, 2020, "The Rising Cost of Climate Change: Evidence from the Bond Market," Working Paper 2020-25, Federal Reserve Bank of San Francisco.

Bazelon, Coleman and Kent Smetters, 1999, "Discounting Inside the Washington D.C. Beltway," Journal of Economic Perspectives, Vol. 13, No. 4, 213-228.

Christensen, Jens H. E., Francis X. Diebold, and Glenn D. Rudebusch, 2009, “An ArbitrageFree Generalized Nelson-Siegel Term Structure Model," Econometrics Journal, Vol. 12, No. 3, C33-C64.

Christensen, Jens H. E., Jose A. Lopez, and Paul L. Mussche, 2021, "Extrapolating LongMaturity Bond Yields for Financial Risk Measurement," forthcoming Management Science.

Christensen, Jens H. E. and Nikola Mirkov, 2021, "The Safety Premium of Safe Assets," Working Paper 2019-28, Federal Reserve Bank of San Francisco.

Christensen, Jens H. E. and Glenn D. Rudebusch, 2016, "Modeling Yields at the Zero Lower Bound: Are Shadow Rates the Solution?," in Eric Hillebrand, Siem Jan Koopman (ed.) Dynamic Factor Models (Advances in Econometrics, Volume 35) Emerald Group Publishing Limited, 75-125.

Christensen, Jens H. E. and Glenn D. Rudebusch, 2019, “A New Normal for Interest Rates? Evidence from Inflation-Indexed Debt," Review of Economics and Statistics, Vol. 101, No. 5, 933-949.

Diebold, Francis X. and Canlin Li, 2006, "Forecasting the Term Structure of Government Bond Yields," Journal of Econometrics, Vol. 130, 337-364.

Duffee, Gregory R., 2002, "Term Premia and Interest Rate Forecasts in Affine Models," Journal of Finance, Vol. 57, No. 1, 405-443. 
Garbade, Kenneth D., 2017a, "Beyond 30: Long-Term Treasury Bond Issuance from 1953 to 1957," Liberty Street Economics, February 6.

Garbade, Kenneth D., 2017b, "Beyond 30: Long-Term Treasury Bond Issuance from 1957 to 1965," Liberty Street Economics, February 6.

Gürkaynak, Refet S., Brian Sack, and Jonathan H. Wright, 2007, "The U.S. Treasury Yield Curve: 1961 to the Present," Journal of Monetary Economics, Vol. 54, No. 8, 22912304 .

Kim, Don H. and Kenneth J. Singleton, 2012, "Term Structure Models and the Zero Bound: An Empirical Investigation of Japanese Yields," Journal of Econometrics, Vol. 170, No. $1,32-49$.

Michalache, Gabriel, 2020, "Sovereign Default Resolution through Maturity Extension," Journal of International Economics, Vol. 125, https://doi.org/10.1016/j.jinteco.2020.103326.

Nelson, Charles R. and Andrew F. Siegel, 1987, "Parsimonious Modeling of Yield Curves," Journal of Business, Vol. 60, No. 4, 473-489.

Novy-Marx, Robert and Joshua D. Rauh, 2009, "The Liabilities and Risks of State-Sponsored Pension Plans," Journal of Economic Perspectives, Vol. 23, No. 4, 191-210.

Svensson, Lars E. O., 1995, "Estimating Forward Interest Rates with the Extended NelsonSiegel Method," Quarterly Review, No. 3, Sveriges Riksbank, 13-26. 